\title{
Gaps in global wildlife trade monitoring leave amphibians vulnerable
}

\author{
Authors \\ Alice C. Hughes ${ }^{1 *+}$, Benjamin M. Marshall ${ }^{2+}$, Colin T. Strine ${ }^{2}$ \\ Affiliations \\ ${ }^{1}$ Centre for Integrative Conservation, Xishuangbanna Tropical Botanical Garden, Chinese \\ ${ }^{2}$ School of Biology, Institute of Science, Suranaree University of Technology, Nakhon \\ Ratchasima, Thailand
}

Corresponding author email

*achughes@xtbg.ac.cn

+contributed equally

\section{Abstract}

As the biodiversity crisis continues, we must redouble efforts to understand and curb pressures pushing species closer to extinction. One major driver is the unsustainable trade of wildlife. Trade in internationally regulated species gains the most research attention, but this only accounts for a minority of traded species and we risk failing to appreciate the scale and impacts of unregulated legal trade. Despite being legal, trade puts pressure on wild species via: direct collection, introduced pathogens, and invasive species. Smaller species-rich vertebrates, such reptiles, fish, and amphibians, may be particularly vulnerable to trading because of gaps in regulations, small distributions, and demand of novel species. Here we combine data from five sources: online web searches in six languages, CITES trade database, LEMIS trade database, IUCN assessments, and a recent literature review, to characterise the global trade in amphibians, and also map use by purpose including meat, pets, medicinal and for research. We show that 1,215 species are being traded (17\% of amphibian species), almost three times previous recorded numbers, 345 are threatened, and 100 data deficient or unassessed. Traded species origin hotspots include South American, China, and Central Africa; sources indicate $42 \%$ of amphibians are taken from the wild. Newly described species can be rapidly traded (mean time lag of 6.5 years), including threatened and unassessed species. The scale and limited regulation of the amphibian trade, paired with the triptych of connected pressures (collection, pathogens, invasive species), warrants a re-examination of the wildlife trade status-quo, application of the precautionary principle in regards to wildlife trade, and a renewed push to achieve global biodiversity goals. 


\section{Keywords}

CITES, LEMIS, online trade, IUCN, endangered species, regulation, wildlife trade

\section{Introduction}

At the close of a "decade of biodiversity" we have failed to meet any of the Aichi targets designed to safeguard biodiversity (CBD, 2020). One important driver of biodiversity loss is unsustainable wildlife exploitation (IPBES, 2019). Countering illegal wildlife trade is critical to limiting biodiversity loss; however, focusing on illegal wildlife trade can miss a potentially greater issue; that of legal wildlife trade. Gaps in trade regulations in terms of species covered by international regulation such as by the Convention on International Trade in Endangered Species (CITES), leaves groups like amphibians and reptiles among the most frequently traded animals (Herrel and van der Meijden., 2014), and largely outside the control of such conventions.

Previous studies aiming to quantify global patterns of trade have relied upon accessible data (such as CITES and IUCN data; i.e., Scheffers et al., 2019); relying on regulator data can miss critical legal unregulated trade, as evidenced by analysis on reptiles which highlighted the proportion of species in trade fall outside the scope of CITES (Marshall et al., 2020). Such analysis risks providing a false sense of assurance that we understand the dimensions of trade, while in reality the trade may be spanning far more species than those actively monitored (Marshall et al., 2020). Marshall et al. (2020) highlighted the discrepancy in protection within the reptile trade, with only $9 \%$ under CITES regulations yet over $36 \%$ in trade and over $70 \%$ of individuals from some taxa (e.g., lizards) coming from the wild. Whilst trade of wild-collected individuals is not necessarily unsustainable, such a judgement should rely on data, as unregulated harvest from the wild, especially for rare or small-ranged species could potentially pose a significant risk to the continued survival of such populations (Auliya et al., 2016).

The need for a complete assessment of amphibian species in trade, their origins, and where native populations are at risk is emphasised by targeted studies revealing high rates (87\% of individual Southeast Asian newts) of wild collection (Rowley et al., 2016). Given that species can be restricted to single drainage basins, unsustainable trade can represent a genuine risk to species future survival; limited trade assessments means that understanding when trade is or is not sustainable simply is not possible for many species, though recent studies show it can have an impact on population viability (Morton et al., 2021).

Despite experiencing similar pressures to reptiles and greater sensitivity to perturbations (Stuart et al., 2004), amphibians are one of the least protected taxa under CITES regulation with only $2.5 \%$ of all known species listed, despite showing faster population declines than any other vertebrate group (Hoffmann et al., 2010). Often dubbed canaries in the coal-mine amphibians are sensitive to a myriad of anthropogenic stressors: pollution (Blaustein et al., 2003), habitat loss (Stuart et al., 2004), atmospheric changes (Blaustein et al., 2003), introduced pathogens 
(Lips, 2016), invasive species (Bellard et al., 2016), wildlife collection (Phimmachak et al., 2012); and agricultural chemicals (Trudeau et al., 2020); such stressors are exacerbated by amphibians' frequently small distributions and naturally fluctuating populations (Nori et al., 2018; Luo et al., 2015; $\mathrm{Hu}$ et al., 2012). Amphibian trade is directly tied to the last three stressors. Trade can enable pathogen spread (O'Hanlon et al., 2018), which has facilitated devastating amphibian species loss (Scheele et al., 2019; but see Lambert et al., 2020 for concerns over the number of species). Invasive amphibians (often linked to trade; Lockwood et al., 2019; Stringham and Lockwood, 2018) can be vectors for pathogen spread (Bienentreu and Lesbarrères, 2020; Feldmeier et al., 2016), but also can compete with native species for resources such as space and prey (Falaschi et al., 2020). Wild collection (directly taking animals from the wild) occurs at several scales: on local levels, humans collecting species for trade, consumption and medicine (Ribas and Poonlaphdecha, 2017; Van Vliet et al., 2017; Onadeko et al., 2011); whereas more widely amphibian trade is augmented by demand for pharmaceutical products, pets and even fashion (Auliya et al., 2016; Xiao et al., 2011).

A recent literature assessment of amphibian pet trade found 443 traded species (Mohanty and Measey, 2019), but as we strive towards ever more complete and representative assessments of the amphibian trade, we must capture trade other than pets, as well as outside of literature (that can often be skewed towards certain languages/regions; Konno et al., 2020). More standardised and comprehensive data are necessary to ensure that wildlife trade avoids harming species' longterm survival prospects; the current lack of data, or lack of transparency or access to baseline population data and compiled trade records frustrates trade mitigation efforts.

Here we aim to map amphibian species in trade, complimenting previous regional efforts (Yap et al., 2015), or those focusing on easily accessible data such as CITES and LEMIS (United States Fish and Wildlife Service's Law Enforcement Management Information System). We explore two major databases of international trade, combining this with an automated web search of amphibian selling websites across six languages. We place these findings in the context of the findings of the Mohanty and Measey study (2019), and species reported as traded in the IUCN Redlist database. In addition we examine the overlap between these five trade data sources, and explore the different trade dimensions they represent, and how the trade may impact wild populations. We further explore where species are coming from and their threatened status, thereby attempting to highlight trade vulnerability hotspots. This study builds towards a comprehensive assessment of amphibian trade, while attempting to highlight how many species are traded, the major drivers of trade, and where these species originate.

\section{Results}

We split our assessment of the trade into: contemporary trade, and all trade. Contemporary trade used three databases which could be examined for trade dynamics (LEMIS 2000-2014, CITES 1975-2019 and Online trade 2004-2020). All trade also included two additional datasets reporting species presence in trade (IUCN trade database; Mohanty \& Measey 2019). 


\section{Dimensions of trade}

Our online search efforts successfully examined a total of 139 amphibian selling websites, and retrieved 2,766 web pages to be searched (mean of $19.91 \pm 3.95$ pages per website; range 1 302). Our temporal online sample (2004-2019) added an additional 4,568 pages, meaning our complete online species list is based on searches across 7,334 pages. We detected 480 keywords (i.e., amphibian scientific names and synonyms) that equated to 442 species in the 2020 snapshot, and 486 keywords that equated to 443 species in the temporal sample, resulting in a total of 575 species detected in the online trade.

Overall, the three data sources (online trade, LEMIS, and CITES trade database) contained 909 species in total (11.06\% of 8,212 amphibian species), of which LEMIS had the most (587 species, $31 \%$ unique), followed by Online trade (575 species, 30\% unique) then CITES (137 species, 4\% unique). Most of this trade was commercial (99.6\%) with only $0.4 \%$ noncommercial. Unsurprisingly anurans (729 species) dominated the trade, followed by salamanders (162 species) and caecilians (18 species). Based on these three databases a total of 157 species were threatened (i.e., listed as Vulnerable or worse on the IUCN Redlist), 27 data deficient, and 39 unassessed (Figure 1).

Whilst the majority of species in trade in CITES have a CITES listing (95\%), this is not the case for species detected via LEMIS (14\%) or online searches $(16 \%)$. In terms of the degree of threat $47 \%$ of species in trade via CITES are threatened and $12 \%$ are unlisted, whereas this is lower for LEMIS $(24 \% ; 5 \%)$ and Online $(23 \% ; 6 \%)$. However, due to the larger number of species traded, species detected via LEMIS and online searches account for a larger proportion of all threatened amphibian species. For example, 4\% of Critically Endangered species and 5\% of Endangered species were detected in trade via LEMIS, compared to $2 \%$ and $3 \%$ for CITES. In total, relying exclusively on CITES would suggest only $3 \%$ of threatened species are traded, whereas LEMIS and online reveal $5 \%$ of threatened species traded.

Mapping reveals a global exploitation of amphibians. However, the number of species exploited in different regions varies dramatically (Figure 2; S1). Both LEMIS and online trade highlight high numbers of species across the tropics, especially in the Amazon. However, LEMIS highlights more traded species in Africa and Southeast Asia, and CITES misses almost all areas with only a fraction of species in the Amazon (poison dart frogs) covered (Figure S2). Particularly high proportions of species were in trade, not only in less diverse regions, but also across tropical Asian regions. In addition, particularly high percentages of species are in trade in South Cambodia and areas of Madagascar (Figure S3).

Many traded species categorised as Vulnerable or worse originate from Asia, in addition to the Mediterranean and various parts of South America (Figure S4), whereas small ranged species are in trade from across the tropics and various islands. At the national level, countries across the Middle East and Southeast Asia had more than half their species in trade classed as either threatened or data-deficient/unassessed. South America, Madagascar and the Caribbean have 
even higher percentages of threatened species in trade. South America and Southeast Asia have the highest numbers of species in trade without CITES regulations.

The LEMIS database provides us with greater insights into the source of the amphibians being traded. Of the trade described in LEMIS 2000-2014, and constituting/representing single individual animals, $99.9 \%$ is not from seizure and enters the USA $(69,688,337 / 69,771,677)$, and the vast majority is for commercial purposes $(69,492,478 / 69,771,677 ; 99.6 \%)$. Of the $69,771,677$ amphibians imported into the USA, recorded by LEMIS, 57.2\% $(39,921,289)$ are listed as captive sourced, leaving $42.3 \%(29,522,128)$ as originating from the wild (the remaining $0.47 \%$, 328,260 , classed as other or with an ambiguous source). The wild capture volumes and percentages vary among genera, from millions of individuals to fewer than 100 (Figure S5-S10). The vast majority of imported genera are impacted by wild capture (254/259) with 141 genera exclusively wild-sourced; five genera are fully sourced from captive operations. On average $84.2 \%$ of each genera's individuals come from the wild, and a per genera median of $100 \%$ is likely driven by the large number of genera exclusively taken from the wild but in much lower volumes (e.g., fewer than 100 individuals, or fewer than 10 individuals per year given the 20002014 timeframe; Figure S10).

\section{Trends over time}

Whilst the CITES trade has remained relatively consistent over time between 2000 and 2020 at around 50 species a year with a gradual increase of species, LEMIS shows an increase up to 2014 (the limit of available data) at 310 species (Figure 3A). The online trade shows much more interannual variation (likely exaggerated by sampling effort fluctuations), increasing to 200 species in 2010, decreasing up to 2014 at under 100 species, then increasing again up to over 200 species in 2019. The number of pages scraped for online trade also followed this trend, peaking at over 1,250 pages in 2014, decreasing to under 200 in 2014 then increasing to over 1,000 in 2018 (Figure 3B). The residuals from a linear regression accounting for the number of pages searched suggests a steady increase in species (Figure 3B).

Thirty eight species described since 2000 (1.38\% of the 2,747 amphibian species described after 1999; Figure 4A, 4B) appeared in trade based on our three databases (and 41 with the addition of two further species described in 2018 and listed for sale in 2020; Altherr and Lameter 2020). Eight only appeared in the 2019 snapshot, so are discounted from time lag calculations, leaving 30 species with connected trade years and a mean time lag of $6.5 \pm 0.78$ years between species description and appearance in the trade. Of the 38 species, 12 are Least Concern, 10 are unevaluated, three are Data Deficient, and 13 are threatened (one of which is critically endangered). One species was in trade the year after it was described, but four were in trade in the second year, four in the third year, and seven within 4-5 years (Figure 4C). We cannot differentiate instances of rapid exploitation after species description from instances of name updates pertaining to species already traded. Although it should be noted that even in these cases given the smaller population sizes and distributions of split species they may be more vulnerable to population declines resulting from wild-harvest. 


\section{Language markets}

Different language searches returned different species lists, with all languages containing species unique to that language. English and German detected the most species by far (293, 289), and each also contained the highest rates of unique species $(81,97)$. German produced a larger list of species, despite similar sampling efforts as Spanish, French, Japanese, and Portuguese (Figure 5). The top websites in terms of species were mostly commercial (6 out of the top ten), two of which prominently advertised wholesale options. The remaining four top websites (including the top website with 278 species) were hosting classified advertisements.

\section{Drivers of demand}

To better capture all the species traded, we combined our contemporary analyses from the three data sources (online trade, LEMIS, and CITES trade database) with the analyses from Mohanty and Measey (2019) and the IUCN list of traded species. Comparisons reveal that different sources detected different species in the trade, and no single source is sufficient to detect all species traded (Figure 6). Combining all sources yielded a total of 1,500 amphibian species in trade before synonyms were removed, and 1,215 once synonyms were removed equivalent to $17 \%$ of amphibian species.

The 1,215 species included up to 413 species used for meat (though a significant number were largely local consumption based on IUCN listings), 805 species as pets (though 6 are from separate lists: one from Germany; Altherr and Lameter 2020; five from Asia-Choquette et al., 2020), 122 species used as medicine or in pharmacological research, and 664 species imported for research or breeding facilities (including zoos and aquaria), other purposes were also listed (various fashion companies such as Prada and Gucci were listed as importers, and some amphibians are imported for bait) but we have not listed these uses separately. In total over 930 were used for other commercial purposes, and 1,215 in total when medicinal/pharmaceutical and research imported species are included. In terms of status, $4 \%$ of species in trade are critically endangered ( $4 \%$ for pets, $4 \%$ for meat), $10 \%$ are data deficient or unassessed $(9 \%$ pets, $11 \%$ meat, over $8 \%$ used in medicine or pharmacology). In total $22 \%$ of species in trade are threatened (i.e., Vulnerable or worse, $28 \%$ when near-threatened are also considered), $25 \%$ for pets, $31 \%$ for meat), $39 \%$ for medical purposes and only $21 \%$ of those used for research. In terms of coverage of species for each type of trade by CITES $(12 \%$ overall 151/1,215) this varied from $5 \%$ of species used for meat, to $16 \%$ of those used for pets or $18 \%$ for medicine, and $16 \%$ of those in research.

Mapping out these patterns also revealed a variety of trends among different uses (Figure 7). In terms of commercial trade, pet trade dominated the global trade of amphibians and the pattern is most similar to the map of all trade with up to 51 species from any given area shown to be in trade for pet trade relative to the 71 from all trade. Trade for meat is more limited with only up to 26 species from any given area in trade, and up to 8 species for medicine or pharmaceutical trade. Interestingly research/zoos were associated with up to 57 species from any given area in trade and broadly mirroring the patterns seen in the pet trade. It should be noted that these may 
be underestimates, as the LEMIS does not specify exact purpose, and it must be inferred from the buyer and type of sale. Whilst the volumes likely differ substantially between animals traded for research relative to commercial sources it highlights the numbers of species potentially vulnerable to at least low levels of international trade. Commercial trade of amphibians for meat is also shown to be from Asia using the United Nations Commodity Trade Statistics Database (UN Comtrade: https://comtrade.un.org/data/) which shows that global export of frog legs is dominated by Indonesia (at $8005997 \mathrm{~kg}$ in 2008-2009 alone), followed by China, Vietnam and other Asian nations with the dominant markets in France, Belgium and the US, though these statistics are only available until 2010 and markets seem to be both growing and diversifying at that point based on data available in the preceding years.

\section{Discussion}

\section{Scale, scope, and vulnerability}

Amphibians are often considered canaries in the coalmine as they are sensitive to pollution and habitat loss making their absence an early warning sign of habitat degradation; sensitivity to change combined with trade, and disease risk creates the perfect storm threatening future amphibian survival.

Whilst regional and some global studies have explored the extent of pet trade (Mohanty and Measey 2019), or meat trade (Carpenter et al., 2014), a well over double the known number of species to be in trade relative to previous studies (i.e., Scheffers et al., 2019, 542 relative to 1,215), as well as a more representative understanding of what is currently in trade and how it has changed over the last two decades. The scope of the amphibian trade is larger than formerly realised with implications for the direct exploitation of these species, disease spread (Schloegel et al., 2009), and the pool of potentially new invasive species (Gippet and Bertelsmeier, 2021). Each dataset we examined included unique species missing from the other datasets (Figure 6), illustrating the need to use multiple sources to characterise wildlife trade, and underscoring the need for a better system to centralise knowledge on what is being traded, and where animals are sourced.

Concerns over the scale and scope of the trade are compounded by the lack of baseline population studies, frustrating efforts to truly understand sustainability of the trade, as understanding sustainable offtake is impossible without baseline population data. A recent metaanalysis on how trade impacts wild populations was unable to generate an estimate on amphibians because of a lack of standardised studies, but revealed abundance declines of $62 \%$ (95\% CI 20-82\%) in traded populations of mammals, birds, and reptiles (Morton et al., 2021). Amphibians in areas with high volumes of exports may be at particular risk given the high rates of wild capture. For example, meat trade is known to impact at least 40 species annually from Indonesia alone (Gratwicke et al., 2010), with many coming directly from the wild, and even captive rearing facilities risk endangering wild species through pathogen exposure unless biosafety standards are improved. Understanding the impacts on source populations requires a 
better understanding of what species are being traded, the volumes in trade and the status of the wild populations is critical for preventing negative impacts on source populations.

Despite the impact of trade, the World Customs Organization still fails to list species data in exports -only basic data is needed to legally export most amphibians, providing no speciesspecific information to enable trade monitoring. With limited baselines on populations and disparate or inaccessible records of trade, we cannot hope to make effective management decisions or develop quotas for sustainable use. A lack of systematic monitoring of global trade limits us to a basic understanding of traded species, origin and impacts on native species. Monitoring deficiencies have been repeatedly highlighted over the past decade, but we still await the policy responses necessary to ensure the survival of vulnerable species (Auliya et al., 2016). In fact, government funding for projects targeting basic monitoring initiatives has dwindled in recent years in favour of applied scientific applications, and "less charismatic" species are most likely to be underfunded (Bellon 2019) and have lower investment in conservation (Gerber 2016).

We show $22 \%$ of the 1,215 species in trade are threatened (i.e., IUCN Redlist status of Vulnerable or worse), and a further $8 \%$ remain unassessed or Data Deficient. One in ten traded species are already extremely vulnerable (11\% of species Endangered or Critically Endangered). The trade extends beyond captive reared or ranched individuals, and is motivated in part by novelty and rarity (as has been documented for the reptile trade previously; Marshall et al., 2020; Lyons and Natusch 2013), potentially further illustrated by the appearance of 38 species described since 2000 in the trade. Whether these new species are the result of species splits or completely novel lineages being described, they highlight the knowledge gaps that need to be addressed before sustainability can be confidently assessed. However, Stringham et al., (2021) note showed that new (reptile) species smuggled in Australia were well predicted by their existence in US markets, thereby suggesting a diminished role for novelty (i.e., recent description) when compared to accessibility. Because of novelty dynamics in trade and the changing taxonomy, CITES appears an inadequate tool to describe taxonomic or spatial trade patterns; CITES misses $97.5 \%$ of species, and fails to provide any default (or sufficiently rapid) protection for newly described and potentially vulnerable species. Tropical regions and islands, with high levels of endemism, still have a significant proportion (often exceeding 1/3 or even half) of species traded indicating the need to expand trade monitoring.

Global monitoring continues to be inadequate; the lack of specificity hinders the utility of global data from the World Customs Organization (Chan et al., 2015). Calls for improvements and increased specificity were made at the IUCN's 5th World Conservation Congress (WCC-2012Res020) in 2012. Changes remain elusive, with details on updates in the World customs organization 2022 edition failing to address animal trade (World Customs Organization 2020). Thus, a decade has passed and reasonable actions for biodiversity are still ignored in economically orientated databases. The dearth of reliable/accessible data (both for baseline population and trade volumes) undermines efforts to determine trade sustainability for the vast 
majority of non-CITES species (i.e., the vast majority of all amphibian species). The trade of endangered and range-limited species, paired with the high rates of wild capture (especially given that this is higher for pets than for other purposes) would suggest much of the trade could be unsustainable and damaging the future survival of species.

\section{Trade and disease}

To date 94 cases out of the 159 extinct and potentially extinct species from the 2008 Global Amphibian Assessment are at least partially attributed to Batrachochytrium dendrobatidis (Bd) (IUCN 2009; Picco and Collins 2008), and suggestions that Bd is likely to be responsible for up to 500 species declines (Scheele et al., 2019; but see Lambert et al., 2020 for discussion on the $500+$ estimate). Furthermore Bd, B. salamandrivorans (Bsal), Ranavirus and a range of other diseases, carried by amphibians and fish, can spread into naïve populations and move between aquatic taxa (Bayley et al., 2013; Mao et al., 1999). With millions of individuals exported annually (peaking at around $5575 \mathrm{~K} \mathrm{~kg}$ from Indonesia alone in a single year in the early 1990s, and fluctuating between $3600 \mathrm{~K}-5000 \mathrm{~K} \mathrm{~kg}$ most years based on LEMIS), no systemic mechanism to ensure correct identity, and poor biosafety standards, water contamination resulting from continued unrestricted/uncontrolled trade is likely to lead to further disease spread and population declines. Rates of $\mathrm{Bd}$ in live exports can be high (over $60 \%$ of individuals), with studies linking the spread of $\mathrm{Bd}$ and Bsal to the trade of live animals in the pet trade (Fitzpatrick et al., 2019; Kriger and Hero 2009). As a consequence of this risk of disease, areas like the European Union have initiated the TRACES (TRAde Control and Expert System) program to attempt to monitor what is imported and associated disease risk. Yet such data is challenging to access and is unlikely to enable proactive monitoring for ecosystem health, despite the development of organisations such as the World Organisation for Animal Health (OIE) (Martel et al., 2020). Though regional networks have developed for specific cases such as $\mathrm{Bd}$ (www.spatialepidemiology.net/bd).

The risk of both recognised and novel invasive pathogens should not be underestimated. Whilst we did not separately map it here, various amphibians are sold commercially as bait. Previous studies show that not only do the live animals kept in bait shops frequently carry fungal and viral pathogens, but they are also frequently released into the wild after use (Picco and Collins 2008). Given that over $40 \%$ of individuals in this study are shown to come directly from the wild, the potential for spread of pathogens to spread to new areas must be addressed to avoid severely impacting native aquatic vertebrate communities (Price et al., 2017).

\section{The necessity for change}

Many papers have highlighted the inadequacies of a CITES paper-based system for monitoring trade (Berec et al., 2018). In the context of amphibians, the discrepancies on reporting (such as species exported from the wild from countries to which they are not native; Auliya et al., 2016) are well documented. Here again we highlight that CITES fails to provide adequate safeguards both for species which are included, and more so for the $97.5 \%$ of amphibian species that are not. 
In recent years, millions of amphibians representing over 1,200 species have been traded, with a considerable portion of individuals coming from the wild. The trade of range limited, data deficient, and newly described species with extremely limited data highlights how harm to species future survival prospects may be occurring out of sight. Inadequate biosafety standards, potential escape, and invasive species in combination with the direct exploitation threatens the future survival of species. The World Customs Organization must urgently address the lack of coding for these species, to enable steps towards sustainable trade. At present only LEMIS enables exact details of species imported and their origins and purchasers, and CITES and other UN conventions must interface better between environmental and economic conventions and targets. The lack of efficacy of coverage within CITES is also underscored by the EU Wildlife Trade Regulations, which build on the number of species under-regulation, but also highlights the need for a more comprehensive system globally.

Whilst developing sustainable quotas for offtake are impossible for species with no data on range or populations, better means to monitor and control trade are necessary and could help form the baseline, especially given that over $40 \%$ of individuals come from the wild. The cost of enabling the status-quo to continue is likely to guarantee the extinction of over-exploited rare species, especially when the number of species traded annually may be increasing. The drive for rare species, entering trade within a few years of description combined with access to more remote areas will expose areas with high endemism to potential exploitation to unsustainable and unmonitored trade, thus better monitoring and reporting standards are needed. Additionally these naïve populations are vulnerable to pathogens and could potentially replicate the patterns of extinction so far seen in the Americas, and drive significant biodiversity loss. Further regulation, and better monitoring of both wild populations and species and individuals traded is urgently needed to slow the decline of populations and loss of species as a consequence of unsustainable, and largely unmonitored trade in wildlife. The precautionary principle should become standard practice to ensure that when trading occurs it is based upon a foundation of data to prevent overexploitation of vulnerable populations, we cannot continue to trade species until we realise that species is already potentially endangered.

\section{Acknowledgments}

We thank the Suranaree University of Technology for providing the resources required to undertake this research. We thank Inês Silva, Ross Creelman, and Akihiro Nakamura for checking translations of search terms.

\section{Funding}

Chinese National Natural Science Foundation (Grant \#:U1602265, Mapping Karst Biodiversity in Yunnan). Supported by the High-End Foreign Experts Program of Yunnan Province (Grant \#:Y9YN021B01, Yunnan Bioacoustic monitoring program). Supported by the CAS 135 program (No. 2017XTBG-T03). 
bioRxiv preprint doi: https://doi.org/10.1101/2021.05.12.443752; this version posted May 13, 2021. The copyright holder for this preprint (which

was not certified by peer review) is the author/funder, who has granted bioRxiv a license to display the preprint in perpetuity. It is made available under aCC-BY 4.0 International license.

\section{Author contributions}

Conceptualization, A.C.H., B.M.M., and C.T.S.; Formal analysis, B.M.M. and A.C.H.; Investigation, B.M.M. and A.C.H.; Methodology, B.M.M. and A.C.H.; Visualization, B.M.M. and A.C.H.; Writing - original draft, A.C.H., B.M.M. and C.T.S.; Writing - review \& editing, A.C.H., B.M.M. and C.T.S.; Supervision, A.C.H.

\section{Competing interests}

Authors declare no competing interests. 


\section{Figure titles and legends}

Figure 1. Breakdown of IUCN Redlist status of traded and not-traded amphibian species. IUCN assessments based on data from AmphibiaWeb. Inclusion as a traded species based on appearance in online searches (20042019 and 2020 online contemporary sample), LEMIS (2000-2014), and CITES data sources (1975-2019).

Figure 2. Percentage of species in trade based on three combined contemporary datasets (LEMIS, CITES, Online (Yellow (0\%)-red-black (100\%))).

Figure 3. Temporal trends in traded species 2000-2019. A) Trends over time of online, LEMIS, and CITES datasets: 1. Raw counts of numbers of species detected in each year, 2. The number of species traded only in a particular year. B) Exploration of trends in online trade: 1. Residuals from the linear regression of number of species detected against number of pages $(d f=13$, intercept $=58.73$, number of pages coef. $=0.13)$, 2 . Number of species per year, 3. Number of archived pages retrieved and searched.

Figure 4. Summary of post-1999 described species and their presence in the trade. A) The post-1999 described species detected in the trade displaying the year of description and the year detected in the trade. B) Shows the species described post-1999 but were only detected in the 2020 snapshot. Alongside species names in A and B are their IUCN Redlist status; on the right of the plot is the CITES appendix, if any, that covers the species. C) Frequency plot showing the count of time lags between description and trade, with colours corresponding to broad summaries of IUCN Redlist status.

Figure 5. Number of species detected via each language in the online search effort. Light blue shows the total number of species per language, and percentage of the overall online species list. Dark blue shows the number of species unique to a particular language and the percentage of that language's species that are unique. Lollipop alongside bars describe the number of websites sampled.

Figure 6. Upset plot showing the coverage and intersection of the five trade data sources. The number of species per order is presented as an illustrative tree, alongside the \% of the total 8,212 amphibian species traded. The number of species that are covered by each CITES Appendix is represented in the bottom left plot (red - not listed, light grey-Appendix I, medium grey - Appendix II, black - Appendix III). N.b., M\&M 2019 is referring to Mohanty and Measey (2019).

Figure 7. Mapping dimensions of trade based on the five data sources. A) pet, B). meat; C). medicinal, D). research and $E$ ). all trade.

\section{Methods}

\section{Website sampling}

We used Google and Bing search engines to discover contemporary websites selling amphibians. We targeted amphibian selling websites in English, French, German, Japanese, Portuguese, and Spanish, to cover the largest herpetofauna pet trade markets. We used appropriately localised versions of the search engines for each language we searched in (Google: https://www.google.com/, https://www.google.fr/, https://www.google.de/, https://www.google.jp/, https://www.google.pt/, https://www.google.es/; Bing: https://www.bing.com/?cc=en, https://www.bing.com/?cc=fr, https://www.bing.com/?cc=de, 
https://www.bing.com/?cc=jp, https://www.bing.com/?cc=pt, https://www.bing.com/?cc=es). Each localised search engine and language was searched with a Boolean search string:

- English: (amphibians OR frogs OR toads OR salamanders OR newts OR axolotls OR caecilians) AND for sale

- French: (amphibiens OR grenouilles OR crapauds OR salamandres OR tritons OR axolotls OR céciliens) AND à vendre

- German: (amphibien OR frösche OR kröten OR salamander OR molche OR axolotls OR caecilian) AND zum verkauf

- Japanese: (爬虫類 OR カエ カル OR ウシガェル OR ヒキガェル OR サンショウウオ OR イモリ OR ウーパールーパー OR アシナシイモリ) AND (売ります OR 販売)

- Portuguese: (anfíbios OR sapos OR sapos OR salamandras OR tritões OR axolotes OR caecilianos OR rãs OR pererecas) AND à venda

- Spanish: (anfibios OR ranas OR sapos OR salamandras OR tritones OR axolotls OR cecilias) AND en venta

We completed the searches in a Firefox private window (Firefox, 2019), while signed out of search engine accounts to minimise the impact of previous search history. Our search terms may have missed specialist sellers, specialising in a single genus/species and advertising only with slang.

We downloaded the first 10 pages of search results provided by each search engine (100 URL search results) to produce a list of 200 URLs per language $(\sim 1,200$ URLs overall). We used assertthat v.0.2.1 (Wickham, 2019a), XML v.3.99.0.3 (Lang and The CRAN Team, 2018) and stringr v.1.4.0 (Wickham, 2019b) to extract all URLs present (Code S1). We filtered out URLs associated with internal search engine links, leaving us with a list of potential amphibian selling websites. We simplified the extracted URLs to their base URL (so all URLs ended in .com, .org, .co.uk etc.), and removed duplicates.

We reviewed each website with the goal of: determining whether the site sells live amphibians, classifying the type of website (classified ads, commercial, other), determining whether the site explicitly forbade automated data collection, identifying a page within the site to initiate data mining, identifying the most appropriate method of data collection, and identifying any ordering in amphibian listings (the last review goal revealed that websites had a mix of ordering; thereby unlikely to bias results: 21 alphabetically, 17 by featured, 12 by date, 5 by price, 2 by popularity, and 30 whose ordering was unclear). If a website did not sell live amphibians, or explicitly forbade automated data collection we excluded it. We randomly assigned all accepted websites with a unique ID for further sampling/analysis (Data S1).

The above sampling process was preregistered on 2020-08-29 (osf.io/x5gse). On 2020-09-11 we completed the preregistered sampling and review of 856 websites; we determined that 104 sites would be suitable for searching. However, this was considerably lower than the 151 websites 
used in previous work (Marshall et al., 2020). Therefore, we completed a second search using a simpler search term ("amphibians for sale", and translations) taking the first five pages from both search engines. The new URLs located in the simpler search were reviewed bringing the total reviewed websites to 1069 and the suitable websites to 139 (906 excluded because they did not sell amphibians, 13 specifically stated no automated searching of the website, 6 were duplicates, and the remaining 5 had issues with access).

\section{Website searching}

We used five methods to collect data from websites, applied hierarchically to minimise server load and the number of irrelevant pages searched (Code S2).

1 - Single page collection. We retrieved a single page, or PDF, for sites that listed the entire stock in a single location. We used the downloader v.0.4 package (Chang, 2015) for the html page retrieval and pdftools v.2.3.1 (Ooms, 2019) to review manually downloaded PDF stock lists.

2 - Cycling through multi-page lists. When stock lists existed on multiple pages, arranged sequentially (e.g., when website's internal search functions return "all amphibians"), we systematically cycled through pages. We identified the maximum search page during website review, and ended page cycling when that maximum was reached or the URL returned an error (e.g., 404 error).

3 - Cycling through multi-page lists, followed by level 1 crawl. If stock lists existed on multiple pages, and the scientific names were only listed behind links on each sequential page, we used the systematically collected pages as a start point for level 1 crawls retrieving all connected pages (i.e., pages holding individual listings or stock details). We used the Rcrawler v.0.1.9.1 package to perform the crawls (Khalil, 2018). We followed the same stop criteria as the basic cycling collection method (method 2$)$.

4 - Base level 1 crawl. When stock was split between groups, we made use of a level 1 crawl to retrieve all pages (Khalil, 2018), setting the page hosting all group links as the start URL.

5 - Base level 2 crawl. When stock was split into multiple levels of groups, we used a level 2 crawl to collect data at each level (Khalil, 2018). For example, stock may be split into "Frogs" and "Salamanders", and within "Frogs" exists links to lists of "Toads", "Tree Frogs", and "Other Frogs".

For methods including crawling, where possible, we selected keywords in the URL to limit the crawl's scope. For example, all stock may be listed in pages with "/products=frogs/" in the URL. The inclusion of a URL keyword filter prevented us from collecting data from irrelevant pages, while lessening time spent crawling and server load. To further reduce the load placed on servers, we included a 10 second delay between requests. We did not pursue results from websites that actively prevented automated data collection. 
In addition to the contemporary sampling of websites, we also sampled for archived web pages originally hosted on Terraristika (https://www.terraristik.com; Code S3). We selected Terraristika to explore the temporal trends in amphibian trade for two reasons: the size of the website and number of species detected in prior contemporary search efforts, and the number of archived web pages available (Marshall et al., 2020). We retrieved archive web pages using the Internet Archive's Wayback Machine API (The Internet Archive, 2013; "The Internet Archive," 2019), by adapting code from the wayback package (Rudis, 2017). We modified the wayback code using the downloader v.0.4 (Chang, 2015), httr v.1.4.2 (Wickham, 2018), jsonlite v.1.7.0 (Ooms, 2014), lubridate v.1.7.9 (Grolemund and Wickham, 2011) and tibble v.3.0.3 packages (Müller and Wickham, 2019).

\section{Keyword usage}

We used species data from AmphibiaWeb as our taxonomic backbone (AmphibiaWeb, 2020; https://amphibiaweb.org/amphib_names.txt; accessed 2020-08-29; Data S2). We created a species list that included all current scientific names and all scientific synonyms. We excluded common names from the keyword list because we did not have common names for all languages nor species, and previous work has shown that common names provide only marginal gains in online data collection efforts (Marshall et al., 2020). We also made no attempt to search for partial names or abbreviations (e.g., Duttaphrynus melanostictus listed as D. melanostictus or D melanostictus).

Prior to the keyword search we undertook basic web page text cleaning. We removed all double spaces, special characters, numbers, and html elements, replacing them with single spaces. The basic cleaning meant that genus and species epithets would appear in the same format as the keyword list provided they occur next to each other on the web page. We used rvest v.0.3.6 (Wickham, 2019c), XML v.3.99.0.3 (Lang and The CRAN Team, 2018), and $x m l 2$ v.1.3.2 (Wickham, Hester and Ooms, 2018) packages to clean and parse the html data.

We used case-insensitive fixed string matching, with stringr v.1.4.0 package (Wickham, 2019b), to search all collected web pages for species names. We used fixed string matching because it has lower computation costs compared with collation matching. Fixed string matching is unable to distinguish between differently coded ligatures or diacritic marks, but our focus on scientific names avoided diacritical marks. Future search efforts using partial or approximate string matching could reveal species we missed if they had only listed with misspelt names or using abbreviations; however, such search efforts would require more computational time, a more thoroughly curated keyword library than what we had access to, and greater caution regarding false positives.

Upon searching a web page for species names, we recorded whether a keyword (species) was present, what accepted species the detected species corresponded to, the page number of the web page, and the website ID (Code S4; Data S3 \& S4). We combined final results from the online search with data from LEMIS and CITES (Code S5). 


\section{Mapping impacts}

To understand the dimensions of trade, and how regions may be impacted with different types of trade we included an additional two data sources (the Mohanty and Measey data based on a collation of published literature, and the IUCN listings of species which state if the species is threatened by trade). We compiled all species on a spreadsheet with the listed purpose from each data-source (Data S5). All species for sale in online stores, we classified as pet trade, whereas the Mohanty and Measey data we classified as "other" and only used these in the total analysis.

For IUCN data the entire list of species listed as "Use and Trade" for food, medicine or pets was downloaded.hese listings were manually processed and those listing food, medicine or pets listed, keywords (food, pets, medicine) were used to make the process more efficient, but as "not" was often included in these statements all listings were manually processed, so checking of all listings to verify status was essential. This was used to classify species by use as food, medicine, pharmaceutical, pet-trade, or other uses. Species for which no form of trade was listed (for example "there is no evidence of trade for this species") were removed from the listings.

For both CITES and LEMIS data the purpose was collated from the commercially imported data as well as the personal data (whilst other categories such as research/zoo were listed directly based on subsets of scientific category data). CITES does not list importer so only coarse categories listed were usable, whereas for LEMIS keywords could be used for both importers and exporters to determine the likely purpose of the item. Firstly, items were split into live and dead. Companies with dead items were likely to be sourcing items for either meat, or pharmaceutical/medicine, whereas live imports could have a variety of purposes, we used a list of keywords associated with the importer and exporter (Data S2) to determine the category each imported item fell into. This still left many items unaccounted for, so as sellers were likely to specialize in one category items were then sorted by seller and other items from that seller listed with the same category. Where a conflict of different listings existed, these were compared to any dead specimens from the same seller, which would indicate that the items were likely to be meat (or medicine/pharmaceuticals). Through this process most items could be sorted to one of the categories, and other suggestive keywords (i.e., "zoo..." in listings not associated with an actual zoo were classed as pets), and then listings of species traded for each purpose collated in a spreadsheet based on all data-sources. Individuals importing species, unless listed for research was also categorized as pets. Whilst there is a degree of uncertainty associated with some of these assigned purposes, it does show that species imported for meat may be a wider selection than realised, as well as those consumed more locally. This was then summed to list the different purposes each species was traded for using LEMIS, and combined with the categories in CITES as well as purposes listed by the IUCN Redlist assessments to produce a list of uses of each species in trade.

For LEMIS summaries of wild capture and captive rearing (Code S6 \& S7; Data S7), we filtered the data to only include items that represented single individuals: whole dead animal (LEMIS code $=$ BOD), live eggs (EGL), dead specimen (DEA), live specimen (LIV), specimen (SPE), 
whole skin (SKI), entire animal trophy (TRO), following the process described in Hierink et al. (2020) and Marshall et al. (2020). We define non-commercial trade as that termed by LEMIS as: Biomedical research $(\mathrm{M})$, Scientific $(\mathrm{S})$, and Reintroduction/introduction into the wild (Y); whereas captive origin covered Animals bred in captivity (C \& F), Commercially bred (D), and Specimens originating from a ranching operation (R); and wild origin only included those listed as Specimens taken from the wild (W). We included all amphibians in origin/purpose summaries, but we only included species detected in LEMIS in final species counts if the full species name listed in LEMIS could be matched to an AmphibiaWeb name or synonym. We relied on LEMIS listing of genus for genera summaries, excluding non-applicable terms (e.g., Non-CITES entry, Anura, Bufonidae, Tadpole).

\section{Mapping and visualisation}

All mapping, bar Figure S1 (which used on AmphibiaWeb ISOCC country data; Code S8), was completed in ArcMap 10.3. Amphibian data range-maps were downloaded from the IUCN (iucnredlist.org) and then species in trade, once corrected for synonyms joined to the shapefile using joins and relates. Individual species maps were then converted into rasters with a resolution of $1 \mathrm{~km}$ using the conversion tools. Mosaic to new raster was then used to quantify the species in trade both altogether, or based upon subsets of data such as endangerment, data source (CITES: Data S8, LEMIS: Data S7, Online: Data S3 \& S4) or use (pet, meat, research, medicinal/pharmaceutical) to provide global maps depicting each type of pressure.

We also explored temporal trends in CITES, LEMIS, and online data, plotting changes over time and using a linear regression to account for search effort online (i.e., pages searched; Code S9). We also plotted the differences in species lists produced by different languages, and summarised the top 10 most-species rich (by number of unique species) websites' purpose (Code S10).

To calculate the level of coverage on and trade on a national basis the IUCN maps were intersected with each country to give a country list, and species lacking range maps were compiled to a national level using AmphibiaWeb data. Endangerment and CITES status for species in trade and not traded were associated with this data using the joins and relates function, and quantified using summary statistics before being rejoined to a global map to assay the level of coverage for species in trade at a National level.

\section{Years of species description}

We retrieved all species years of description from the Amphibian Species of the World database (accessed 2020-10-02; Frost, 2020). We used rvest v.0.3.6 (Wickham, 2019c), and xml2 v.1.3.2 (Wickham, Hester and Ooms, 2018) to call and retrieve the top search result from the database on a species-by-species basis (each AmphibiaWeb species binomial being used a search term), saving the full character string detailing the species authority (Code S10 \& S11). We double checked the retrieved species authority contained the required species binomial. In cases where species binomial was not included (174), we used similiars v.0.1.0 (2020) to detect minor spelling differences. Ultimately, we found 12 species with non-matching authorities and were 
detected in the trade; for these 12 species we manually found the appropriate authority. We used LEMIS, CITES (Data S9), and the online sampling to determine the earliest instance of a species appearing in the trade.

\section{Software and data availability}

We completed all keyword searches and data review in $R$ v.3.6.3 (R Core Team, 2020) and $R$ Studio v.1.4.669 (R Studio Team, 2020). During data manipulation we also made use of $\mathrm{R}$ packages: dplyr v.1.0.2 (Wickham et al., 2020), and tidyr v.1.1.2 (Wickham and Henry, 2019); for data visualisation we used cowplot v.1.1.0 (Wilke, 2019), ggplot2 v.3.3.2 (Wickham, 2016), ggpubr v.0.4.0 (Kassambara, 2018), ggtext v.0.1.1 (Wilke, 2020), glue v.1.4.2 (Hester, 2020), maps v.3.3.0 (Becker et al., 2018), scico v.1.2.0 (Peterson and Crameri, 2018), and UpSetR v.1.4.0 (Gehlenborg, 2019). We added additional details to the upset plot using Affinity Designer v.1.8.5.703 (Serif, 2020).

We have made code used to search online, filter LEMIS data, generate figures 1, 3-5, S4, and elements of 6, and retrieve species authorities available at Open Science Framework: https://osf.io/x5gse/?view_only=27109adbb3364dd2b9115752fd912b99. Alongside the code, we have provided all datasheets listed as supplementary material. 


\section{Supplemental Information titles and legends}

Figure S1. Map of trade by country derived from online, LEMIS, and CITES trade data, and mapped using AmphibiaWeb distribution data. A) the number of amphibian species present in a country. B) the number of species present in that country and also present in the trade. $C$ ) the \% of species found in a country that are traded.

Figure S2. Maps of species diversity by data source (LEMIS, Online, CITES)

Figure S3. Maps of National statistics of species with different IUCN Redlist status and CITES listing in trade.

Figure S4. Maps of threatened species in trade based on the three databases.

Figure S5. Bar chart showing the number and origin of imported individuals per genera, subset to genera with over 1,000,000 individuals recorded. Data from LEMIS 2000-2014. Red indicates those originating from the wild, Blue indicates those originating from captive operations (animals bred in captivity, commercially bred, and originating from a ranching operation). Labels top and bottom show the percentage of that genera from the wild or captive sources. Summary statistics per genera are provided in the caption.

Figure S6. Bar chart showing the number and origin of imported individuals per genera, subset to genera with between 1,000,000 and 100,000 individuals recorded. Data from LEMIS 2000-2014. Red indicates those originating from the wild, Blue indicates those originating from captive operations (animals bred in captivity, commercially bred, and originating from a ranching operation). Labels top and bottom show the percentage of that genera from the wild or captive sources. Summary statistics per genera are provided in the caption.

Figure S7. Bar chart showing the number and origin of imported individuals per genera, subset to genera with between 100,000 and 10,000 individuals recorded. Data from LEMIS 2000-2014. Red indicates those originating from the wild, Blue indicates those originating from captive operations (animals bred in captivity, commercially bred, and originating from a ranching operation). Summary statistics per genera are provided in the caption.

Figure S8. Bar chart showing the number and origin of imported individuals per genera, subset to genera with between 10,000 and 1,000 individuals recorded. Data from LEMIS 2000-2014. Red indicates those originating from the wild, Blue indicates those originating from captive operations (animals bred in captivity, commercially bred, and originating from a ranching operation). Summary statistics per genera are provided in the caption.

Figure S9. Bar chart showing the number and origin of imported individuals per genera, subset to genera with between 1,000 and 100 individuals recorded. Data from LEMIS 2000-2014. Red indicates those originating from the wild, Blue indicates those originating from captive operations (animals bred in captivity, commercially bred, and originating from a ranching operation). Summary statistics per genera are provided in the caption.

Figure S10. Bar chart showing the number and origin of imported individuals per genera, subset to genera with fewer than 100 individuals recorded. Data from LEMIS 2000-2014. Red indicates those originating from the wild, Blue indicates those originating from captive operations (animals bred in captivity, commercially bred, and originating from a ranching operation). Summary statistics per genera are provided in the caption.

Data S1. Website review and sampling ("Target Websites Censored.csv")

Data S2. Original AmphibiaWeb data (“AmphibiaWeb 2020-08-29.csv”)

Data S3. Online search results from the contemporary sample ("Snapshot Online Data.csv”) 
Data S4. Online search results from the temporal sample ("Temporal Online Data.csv")

Data S5. Species listed purposes from each data source ("new_list_amp_jan_FINAL.csv")

Data S6. List of keywords associated the importers and exporters ("supplement_trade_keywords.csv")

Data S7. Filtered LEMIS data with AmphibiaWeb compatible names ("LEMIS Data AmphiNames.csv")

Data S8. Filter CITES appendix data (“Index_of_CITES_Species_[CUSTOM]_2020-09-20 15_51.csv”)

Data S9. Filtered CITES data ("gross_imports_2020-09-2015_25_comma_separated.csv")

Data S10. The final dataset (“Amphibians_in_trade.csv”)

Data S11. The final dataset metadata (“Amphibians_in_trade_METADATA.csv”)

Code S1. Code used to extract URLs from saved search result pages.

Code S2. Code to collect website data using the hierarchical search method

Code S3. Code to collect website data from the wayback machine

Code S4. Code used to implement string matching searches for species keywords

Code S5. Code used to compile website search results with LEMIS and CITES data

Code S6. Code used to filter initial LEMIS data

Code S7. Code used to summarise and explore LEMIS data

Code S8. Code used to generate summary figures

Code S9. Code used to generate figures showing change over time

Code S10. Code used to plot the different species counts between languages used during online searches.

Code S11. Code used to retrieve species authorities

Code S12. Code used to calculate and plot lag times between species description and appearance in the trade.

\section{References}

Altherr, S., \& Lameter, K. (2020). The rush for the rare: Reptiles and amphibians in the European pet trade. Animals, 10(11), 2085. https://doi.org/10.3390/ani10112085

Auliya, M., García-Moreno, J., Schmidt, B. R., Schmeller, D. S., Hoogmoed, M. S., Fisher, M. C., ... \& Martel, A. (2016). The global amphibian trade flows through Europe: the need for enforcing and improving legislation. Biodiversity and conservation, 25(13), 2581-2595. http://hdl.handle.net/1854/LU-8515142 
Bayley, A. E., Hill, B. J., \& Feist, S. W. (2013). Susceptibility of the European common frog Rana temporaria to a panel of ranavirus isolates from fish and amphibian hosts. Diseases of aquatic organisms, 103(3), 171-183. https://doi.org/10.3354/dao02574

Bellard, C., Genovesi, P., \& Jeschke, J. M. (2016). Global patterns in threats to vertebrates by biological invasions. Proceedings of the Royal Society B: Biological Sciences, 283(1823), 20152454. https://doi.org/10.1098/rspb.2015.2454

Bellon, A. M. (2019). Does animal charisma influence conservation funding for vertebrate species under the US Endangered Species Act?. Environmental Economics and Policy Studies, 21(3), 399-411. https://doi.org/10.1007/s10018-018-00235-1

Berec, M., Vršecká, L., \& Šetlíková, I. (2018). What is the reality of wildlife trade volume? CITES Trade Database limitations. Biological Conservation, 224, 111-116. https://doi.org/ 10.1016/j.biocon.2018.12.006

Bienentreu, J.-F., Lesbarrères, D., 2020. Amphibian Disease Ecology: Are We Just Scratching the Surface? Herpetologica 76, 153-166. https://doi.org/10.1655/0018-0831-76.2.153

Blaustein, A. R., Romansic, J. M., Kiesecker, J. M., \& Hatch, A. C. (2003). Ultraviolet radiation, toxic chemicals and amphibian population declines. Diversity and distributions, 9(2), 123-140. https://doi.org/10.1046/j.1472-4642.2003.00015.x

Carpenter, A. I., Andreone, F., Moore, R. D., \& Griffiths, R. A. (2014). A review of the international trade in amphibians: the types, levels and dynamics of trade in CITES-listed species. Oryx, 48(4), 565-574. https://doi.org/10.1017/S0030605312001627

CBD (2020) Global Biodiversity Outlook 5. Montreal. (ISBN-9789292256883) https://www.cbd.int/gbo/gbo5/publication/gbo-5-en.pdf

Chan, H. K., Zhang, H., Yang, F., \& Fischer, G. (2015). Improve customs systems to monitor global wildlife trade. Science, 348(6232), 291-292. https://doi.org/10.1126/science.aaa3141

Choquette, R. E., Angulo, A., Bishop, P. J., Phan, C. T., \& Rowley, J. J. (2020). The internetbased Southeast Asia amphibian pet trade.TRAFFIC Bulletin,32(2), 69. https://www.traffic.org/site/assets/files/13362/seasia-amphibian-pet-trade.pdf

Falaschi, M., Melotto, A., Manenti, R., Ficetola, G.F., (2020). Invasive Species and Amphibian Conservation. Herpetologica 76, 216-227. https://doi.org/10.1655/0018-0831-76.2.216.

Feldmeier, S., Schefczyk, L., Wagner, N., Heinemann, G., Veith, M., Lötters, S., (2016). Exploring the Distribution of the Spreading Lethal Salamander Chytrid Fungus in Its Invasive Range in Europe - A Macroecological Approach. PLOS ONE 11, e0165682. https://doi.org/10.1371/journal.pone.0165682 
Fitzpatrick, L. D., Pasmans, F., Martel, A., \& Cunningham, A. A. (2018). Epidemiological tracing of Batrachochytrium salamandrivorans identifies widespread infection and associated mortalities in private amphibian collections. Scientific reports, 8(1), 1-10. https://doi.org/10.1038/s41598-018-31800-z

Gerber, L. R. (2016). Conservation triage or injurious neglect in endangered species recovery. Proceedings of the National Academy of Sciences, 113(13), 3563-3566. https://doi.org/10.1073/pnas.1525085113

Gippet, J. M., \& Bertelsmeier, C. (2021). Invasiveness is linked to greater commercial success in the global pet trade. Proceedings of the National Academy of Sciences, 118(14), e2016337118. https://doi.org/10.1073/pnas.2016337118

Gratwicke, B., Evans, M. J., Jenkins, P. T., Kusrini, M. D., Moore, R. D., Sevin, J., \& Wildt, D. E. (2010). Is the international frog legs trade a potential vector for deadly amphibian pathogens?. Frontiers in Ecology and the Environment, 8(8), 438-442. https://doi.org/10.1890/090111

Herrel, A., \& van der Meijden, A. (2014). An analysis of the live reptile and amphibian trade in the USA compared to the global trade in endangered species. The Herpetological Journal, 24(2), 103-110. https://www.thebhs.org/publications/the-herpetological-journal/volume-24-number-2april-2014/741-05-an-analysis-of-the-live-reptile-and-amphibian-trade-in-the-usa-compared-tothe-global-trade-in-endangered-species

Hierink, F. et al. (2020). Forty-four years of global trade in CITES-listed snakes: trends and implications for conservation and public health. Biol. Conserv. 248, 108601. https://doi.org/10.1016/j.biocon.2020.108601

Hoffmann, M., Hilton-Taylor, C., Angulo, A., Böhm, M., Brooks, T. M., Butchart, S. H., ... \& Veloso, A. (2010). The impact of conservation on the status of the world's vertebrates. Science, 330(6010), 1503-1509.

Hu, J., Li, C., Xie, F., \& Jiang, J. (2012) Endemic Amphibians and their Distribution in China. Asian Herpetological Research. 3(2): 163-171. https://doi.org/10.3724/sp.j.1245.2012.00163

IPBES. (2019). Summary for Policymakers of the Global Assessment Report on Biodiversity and Ecosystem Services of the Intergovernmental Science-Policy Platform on Biodiversity and Ecosystem Services (IPBES secretariat, Bonn, Germany, 2019). https://doi.org/10.5281/zenodo.3553579

Konno, K., Akasaka, M., Koshida, C., Katayama, N., Osada, N., Spake, R., Amano, T., 2020. Ignoring non-English-language studies may bias ecological meta-analyses. Ecol. Evol. 10, 63736384. https://dx.doi.org/10.1002\%2Fece3.6368 
Kriger, K. M., \& Hero, J. M. (2009). Chytridiomycosis, amphibian extinctions, and lessons for the prevention of future panzootics. EcoHealth, 6(1), 6. https://doi.org/10.1007/s10393-009$0228-y$

Lambert MR, Womack MC, Byrne AQ, Hernández-Gómez O, Noss CF, Rothstein AP, Blackburn DC, Collins JP, Crump ML, Koo MS, Nanjappa P, Rollins-Smith L, Vredenburg VT, Rosenblum EB. 2020. Comment on "Amphibian fungal panzootic causes catastrophic and ongoing loss of biodiversity." Science 367:eaay1838. https://doi.org/10.1126/science.aay1838.

Lips KR. 2016. Overview of chytrid emergence and impacts on amphibians. Philosophical Transactions of the Royal Society B: Biological Sciences 371:20150465. https://doi.org/10.1098/rstb.2015.0465.

Lockwood, J. L., Welbourne, D. J., Romagosa, C. M., Cassey, P., Mandrak, N. E., Strecker, A., ... \& Keller, R. (2019). When pets become pests: the role of the exotic pet trade in producing invasive vertebrate animals. Frontiers in Ecology and the Environment, 17(6), 323-330. https://doi.org/10.1002/fee.2059

Luo, Z., Wei, S., Zhang, W., Zhao, M., Wu, H., 2015. Amphibian biodiversity congruence and conservation priorities in China: Integrating species richness, endemism, and threat patterns. Biol. Conserv. 191, 650-658. http://dx.doi.org/10.1016/j.biocon.2015.08.028

Lyons, J. A., \& Natusch, D. J. (2013). Effects of consumer preferences for rarity on the harvest of wild populations within a species. Ecological Economics, 93, 278-283. https://doi.org/10.1016/j.ecolecon.2013.06.004

Mao, J., Green, D. E., Fellers, G., \& Chinchar, V. G. (1999). Molecular characterization of iridoviruses isolated from sympatric amphibians and fish. Virus research, 63(1-2), 45-52. https://doi.org/10.1016/s0168-1702(99)00057-x

Marshall BM, Strine CT, Hughes AC. 2020. Thousands of reptile species threatened by underregulated global trade. Nature Communications 11(4738). https://doi.org/10.1038/s41467-020$18523-4$

Martel, A., Vila-Escale, M., Fernández-Giberteau, D., Martinez-Silvestre, A., Canessa, S., Van Praet, S., ... \& Picart, M. (2020). Integral chain management of wildlife diseases. Conservation Letters, 13(2), e12707. https://doi.org/10.1111/conl.12707

Measey, J., Basson, A., Rebelo, A. D., Nunes, A. L., Vimercati, G., Louw, M., \& Mohanty, N. P. (2019). Why have a pet amphibian? Insights from YouTube. Frontiers in Ecology and Evolution, 7, 52. https://doi.org/10.3389/fevo.2019.00052

Mohanty, N. P., \& Measey, J. (2019). The global pet trade in amphibians: species traits, taxonomic bias, and future directions. Biodiversity and Conservation, 28(14), 3915-3923. http://dx.doi.org/10.1007/s10531-019-01857-x 
Morton, O., Scheffers, B.R., Haugaasen, T. and Edwards, D.P., 2021. Impacts of wildlife trade on terrestrial biodiversity. Nature Ecology \& Evolution, pp.1-9

Natusch, D. J., \& Lyons, J. A. (2012). Exploited for pets: the harvest and trade of amphibians and reptiles from Indonesian New Guinea. Biodiversity and Conservation, 21(11), 2899-2911. https://doi.org/10.1007/s10531-012-0345-8

Nori, J., Villalobos, F., Loyola, R., 2018. Global priority areas for amphibian research. J. Biogeogr. 45, 2588-2594. https://doi.org/10.1111/jbi.13435

O’Hanlon SJ, Rieux A, Farrer RA, Rosa GM, Waldman B, Bataille A, Kosch TA, Murray KA, Brankovics B, Fumagalli M, Martin MD, Wales N, Alvarado-Rybak M, Bates KA, Berger L, Böll S, Brookes L, Clare F, Courtois EA, Cunningham AA, Doherty-Bone TM, Ghosh P, Gower DJ, Hintz WE, Höglund J, Jenkinson TS, Lin C, Laurila A, Loyau A, Martel A, Meurling S, Miaud C, Minting P, Pasmans F, Schmeller DS, Schmidt BR, Shelton JMG, Skerratt LF, Smith F, Soto-Azat C, Spagnoletti M, Tessa G, Toledo LF, Valenzuela-Sánchez A, Verster R, Vörös J, Webb RJ, Wierzbicki C, Wombwell E, Zamudio KR, Aanensen DM, James TY, Gilbert MTP, Weldon C, Bosch J, Balloux F, Garner TWJ, Fisher MC. 2018. Recent Asian origin of chytrid fungi causing global amphibian declines. Science 360:621-627. https://doi.org/10.1126/science.aar1965.

Onadeko, A.B., Egonmwan, R.I., Saliu, J.K., 2011. Edible Amphibian Species: Local Knowledge of their Consumption in Southwest Nigeria and their Nutritional Value. West Afr. J. Appl. Ecol. 19. https://doi.org/10.4314/wajae.v19i1.

Phimmachak, S., Stuart, B. L., \& Sivongxay, N. (2012). Distribution, natural history, and conservation of the Lao newt (Laotriton laoensis)(Caudata: Salamandridae). Journal of Herpetology, 46(1), 120-128. https://doi.org/10.1670/11-044

Picco, A. M., \& Collins, J. P. (2008). Amphibian commerce as a likely source of pathogen pollution. Conservation Biology, 22(6), 1582-1589. https://doi.org/10.1111/j.15231739.2008.01025.x

Price, S. J., Ariel, E., Maclaine, A., Rosa, G. M., Gray, M. J., Brunner, J. L., \& Garner, T. W. (2017). From fish to frogs and beyond: Impact and host range of emergent ranaviruses. Virology, 511, 272-279. https://doi.org/10.1016/j.virol.2017.08.001

Ribas, A., Poonlaphdecha, S., 2017. Wild-Caught and Farm-Reared Amphibians are Important Reservoirs of Salmonella, A Study in North-East Thailand. Zoonoses Public Health 64, 106-110. https://doi.org/10.1111/zph.12286

Rowley, J. J., Shepherd, C. R., Stuart, B. L., Nguyen, T. Q., Hoang, H. D., Cutajar, T. P., ... \& Phimmachak, S. (2016). Estimating the global trade in Southeast Asian newts. Biological Conservation, 199, 96-100. https://doi.org/10.1016/j.biocon.2016.05.001 
Scheele, B. C., Pasmans, F., Skerratt, L. F., Berger, L., Martel, A. N., Beukema, W., ... \& Canessa, S. (2019). Amphibian fungal panzootic causes catastrophic and ongoing loss of biodiversity. Science, 363(6434), 1459-1463. https://doi.org/10.1126/science.aav0379

Scheffers, B. R., Oliveira, B. F., Lamb, I., \& Edwards, D. P. (2019). Global wildlife trade across the tree of life. Science, 366(6461), 71-76. https://doi.org/10.1126/science.aav5327

Stringham, O. C., \& Lockwood, J. L. (2018). Pet problems: biological and economic factors that influence the release of alien reptiles and amphibians by pet owners. Journal of Applied Ecology, 55(6), 2632-2640. https://doi.org/10.1111/1365-2664.13237

Stringham, O., García-Díaz, P., Toomes, A., Mitchell, L., Ross, J. V., \& Cassey, P. (2021, January 28). Reptile smuggling is predicted by trends in the legal exotic pet trade. https://doi.org/10.32942/osf.io/t42fd

Stuart, S. N., Chanson, J. S., Cox, N. A., Young, B. E., Rodrigues, A. S., Fischman, D. L., \& Waller, R. W. (2004). Status and trends of amphibian declines and extinctions worldwide. Science, 306(5702), 1783-1786. https://doi.org/10.1126/science.1103538

Trudeau, V. L., Thomson, P., Zhang, W. S., Reyaud, S., Navarro-Martin, L., \& Langlois, V. S. (2020). Agrochemicals disrupt multiple endocrine axes in amphibians. Molecular and cellular endocrinology, 110861.

Van Vliet, N., Moreno Calderón, J.L., Gómez, J., Zhou, W., Fa, J.E., Golden, C., Nóbrega Alves, R.R., Nasi, R., 2017. Bushmeat and human health: Assessing the evidence in tropical and subtropical forests. https://dx.doi.org/10.15451/ec2017-04-6.3-1-45

World Customs Organization (2020) The new 2022 Edition of the Harmonized System has been accepted http://www.wcoomd.org/en/media/newsroom/2020/january/the-new-2022-edition-ofthe-harmonized-system-has-been-accepted.aspx 08 January 2020

Xiao, Y., Liu, C. \& Lai, R. (2011). Antimicrobial peptides from amphibians. , 2(1-2), 27-38. https://doi.org/10.1515/bmc.2011.006

Yap, T. A., Koo, M. S., Ambrose, R. F., Wake, D. B., \& Vredenburg, V. T. (2015). Averting a North American biodiversity crisis. Science, 349(6247), 481-482.

https://doi.org/10.1126/science.aab1052

\section{Refences from methods}

AmphibiaWeb. 2020. AmphibiaWeb. Berkeley, CA, USA: University of California. https://amphibiaweb.org/amphib_names.txt; accessed 2020-08-29

Becker OS code by RA, Minka ARWR version by RBE by TP, Deckmyn A. 2018. maps: Draw Geographical Maps. https://cran.r-project.org/web/packages/maps/index.html 
Chang W. 2015. downloader: Download Files over HTTP and HTTPS. https://cran.rproject.org/package $=$ downloader

Firefox. 2019. Mozilla. https://www.mozilla.org/en-GB/firefox/new/

Frost, Darrel R. 2020. Amphibian Species of the World: an Online Reference. Version 6.12020 10-02. Electronic Database accessible at https://amphibiansoftheworld.amnh.org/index.php. American Museum of Natural History, New York, USA. doi.org/10.5531/db.vz.0001. accessed 2020-10-02

Gehlenborg N. 2019. UpSetR: A More Scalable Alternative to Venn and Euler Diagrams for Visualizing Intersecting Sets. https://cran.r-project.org/package=UpSetR

Grolemund G, Wickham H. 2011. Dates and Times Made Easy with \{lubridate\}. Journal of Statistical Software 40:1-25. http://dx.doi.org/10.18637/jss.v040.i03

Hester J. 2020. glue: Interpreted String Literals. https://cran.r-project.org/package=glue

Kassambara A. 2018. ggpubr: "ggplot2" based publication ready plots. https://cran.rproject.org/package $=$ ggpubr

Khalil S. 2018. Rcrawler: Web Crawler and Scraper. https://cran.r-project.org/package=Rcrawler Lang DT, The CRAN Team. 2018. XML: Tools for Parsing and Generating XML Within R and S-Plus. https://cran.r-project.org/package=XML

Müller K, Wickham H. 2019. tibble: Simple Data Frames. https://cran.rproject.org/package=tibble

Ooms J. 2014. The jsonlite Package: A Practical and Consistent Mapping Between JSON Data and R Objects. arXiv:1403.2805 [stat.CO]. https://arxiv.org/abs/1403.2805

Ooms J. 2019. pdftools: Text Extraction, Rendering and Converting of PDF Documents. https://cran.r-project.org/package=pdftools

Pedersen TL, Crameri F. 2018. scico: Colour Palettes Based on the Scientific Colour-Maps. https://cran.r-project.org/package=scico

R Core Team. 2020. R: A language and environment for statistical computing. Vienna, Austria: R Foundation for Statistical Computing. https://www.r-project.org/

R Studio Team. 2020. RStudio: Integrated Development Environment for R. Boston, MA: RStudio, Inc. https://rstudio.com/

Rudis B. 2017. wayback: Tools to Work with Internet Archive Wayback Machine APIs. https://hrbrmstr.github.io/wayback/index.html

Serif. 2020. Affinity Designer. Nottingham, UK: Serif Europe Ltd. https://www.serif.com/en-gb/ 
Sjoberg D. 2020. similiars: Matches strings to most similiar string. https://github.com/davidsjoberg/similiars

The Internet Archive. 2013. Wayback CDX Server API. The Internet Archive. https://github.com/internetarchive/wayback/blob/master/wayback-cdx-server/README.md

The Internet Archive. 2019. Available at https://archive.org/ (accessed November 14, 2019).

Wickham H. 2016. ggplot2: Elegant Graphics for Data Analysis. Springer-Verlag New York. https://doi.org/10.1007/978-0-387-98141-3

Wickham H. 2018. httr: Tools for Working with URLs and HTTP. https://cran.rproject.org/package $=$ httr

Wickham H. 2019a. assertthat: Easy Pre and Post Assertions. https://cran.rproject.org/package=assertthat

Wickham H. 2019b. stringr: Simple, consistent wrappers for common string operations. https://cran.r-project.org/package=stringr

Wickham H. 2019c. rvest: Easily Harvest (Scrape) Web Pages. https://cran.rproject.org/package $=$ rvest

Wickham H, François R, Henry L, Müller K. 2020. dplyr: A Grammar of Data Manipulation. https://cran.r-project.org/package=dplyr

Wickham H, Henry L. 2019. tidyr: Easily Tidy Data with "spread()" and "gather()" Functions. https://cran.r-project.org/package=tidyr

Wickham H, Hester J, Ooms J. 2018. xml2: Parse XML. https://cran.r-project.org/package=xml2 Wilke CO. 2019. cowplot: Streamlined plot theme and plot annotations for "ggplot2." https://cran.r-project.org/package=cowplot

Wilke CO. 2020. ggtext: Improved text rendering support for "ggplot2." https://cran.rproject.org/package $=$ ggtext

\section{Figures}

Figure. 1 


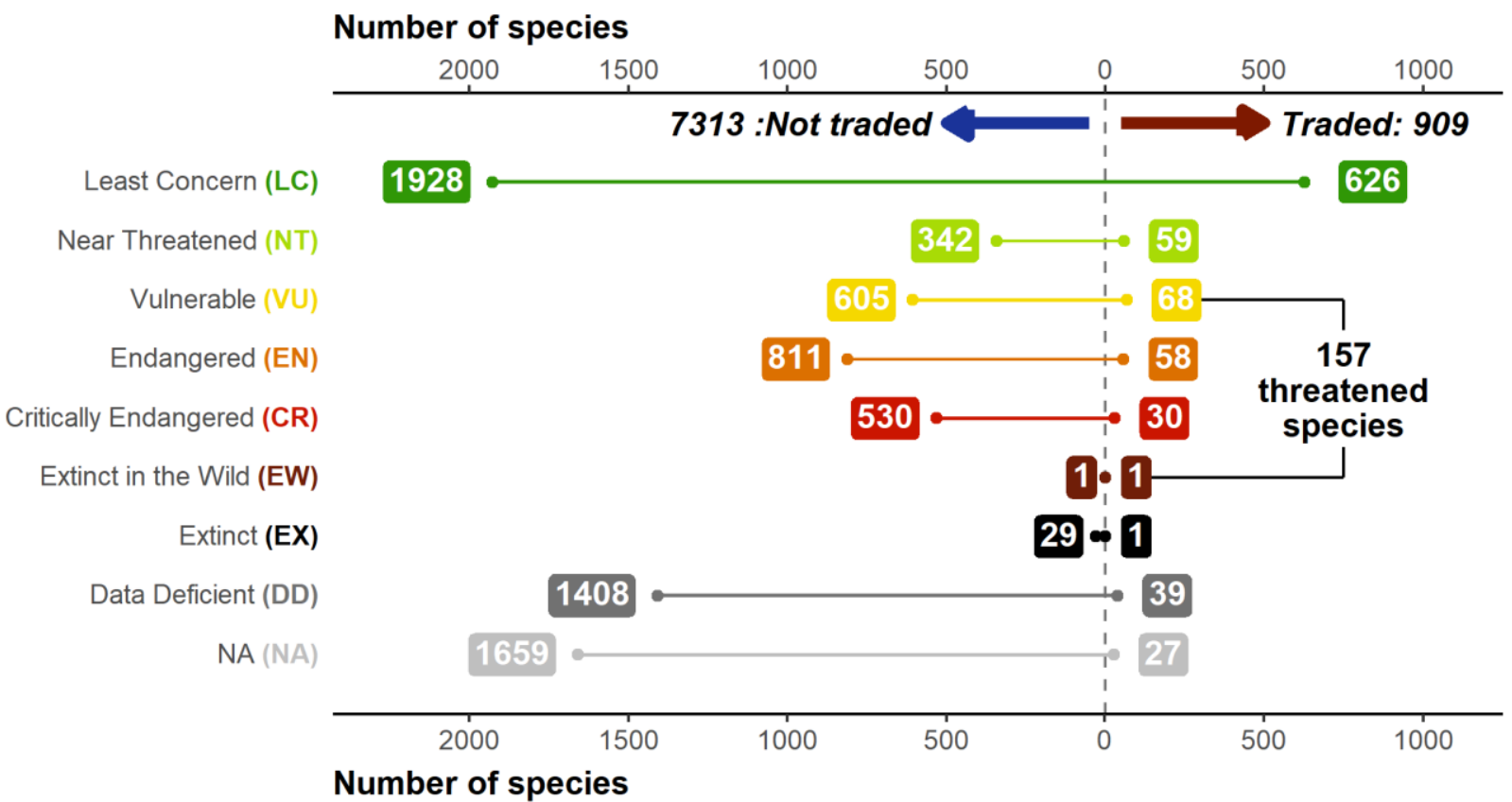

Figure. 2

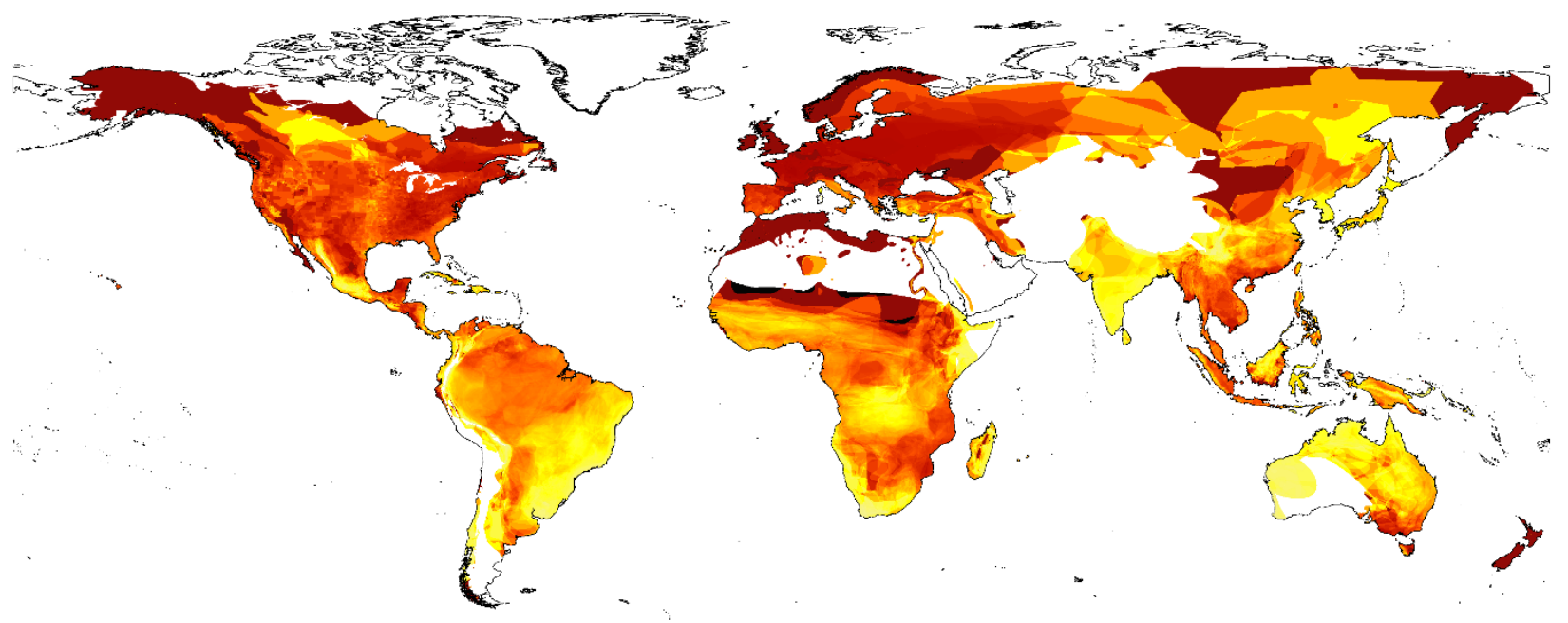

Figure. 3 


\section{A \# of species}

\# of unique species traded

\section{B Residuals}

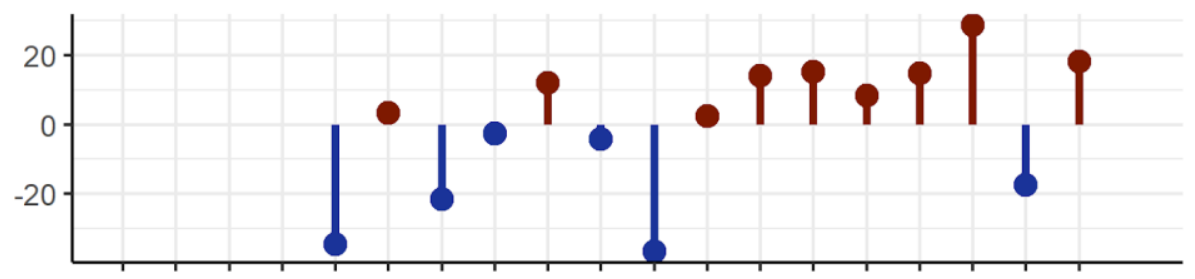

\# of species

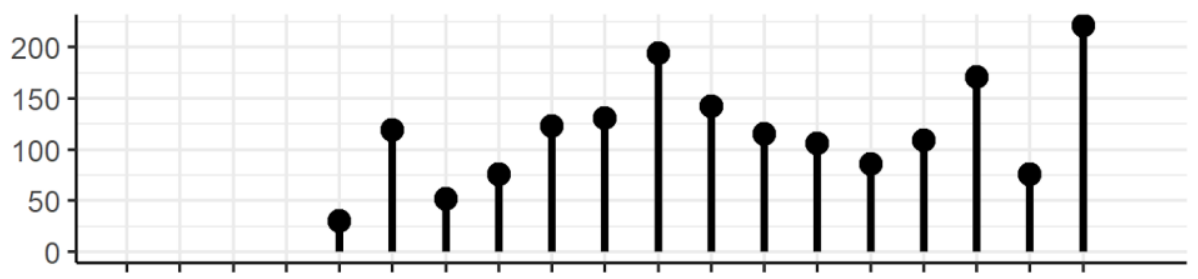

\# of pages

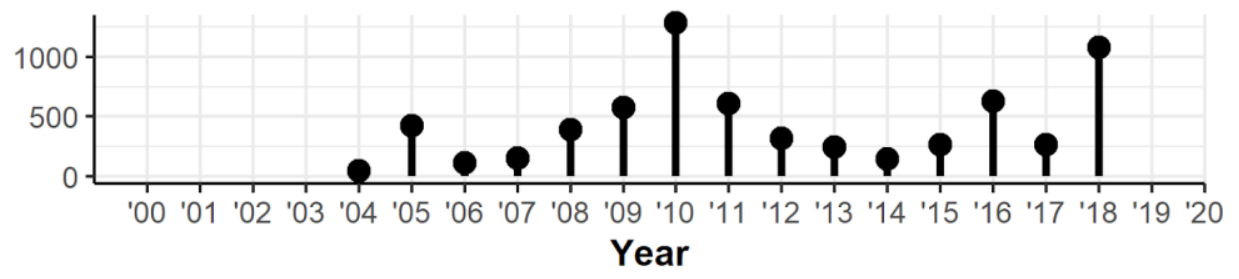

Figure. 4 
bioRxiv preprint doi: https://doi.org/10.1101/2021.05.12.443752; this version posted May 13, 2021. The copyright holder for this preprint (which

was not certified by peer review) is the author/funder, who has granted bioRxiv a license to display the preprint in perpetuity. It is made available under aCC-BY 4.0 International license.

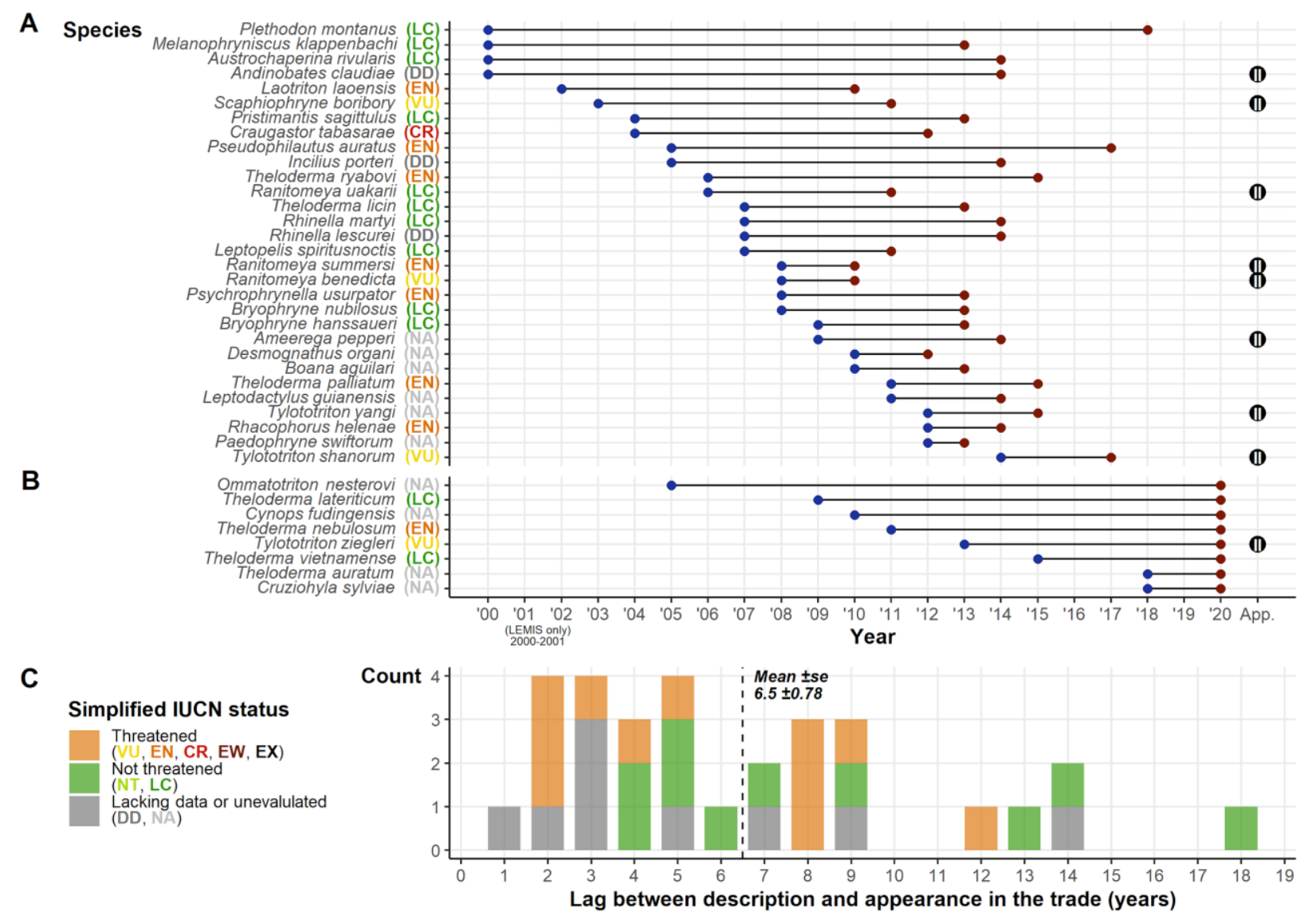

Figure. 5 


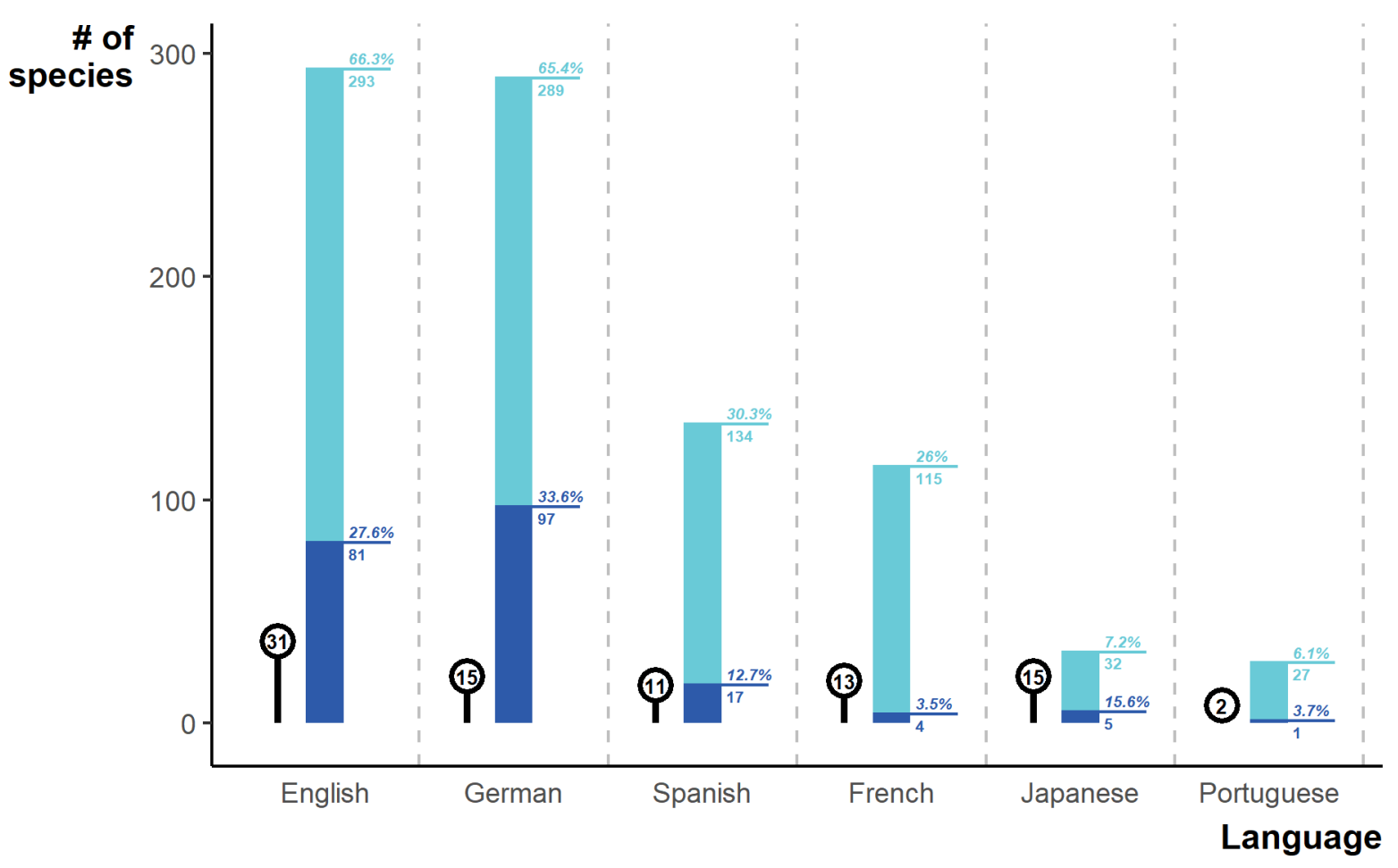

Figure. 6

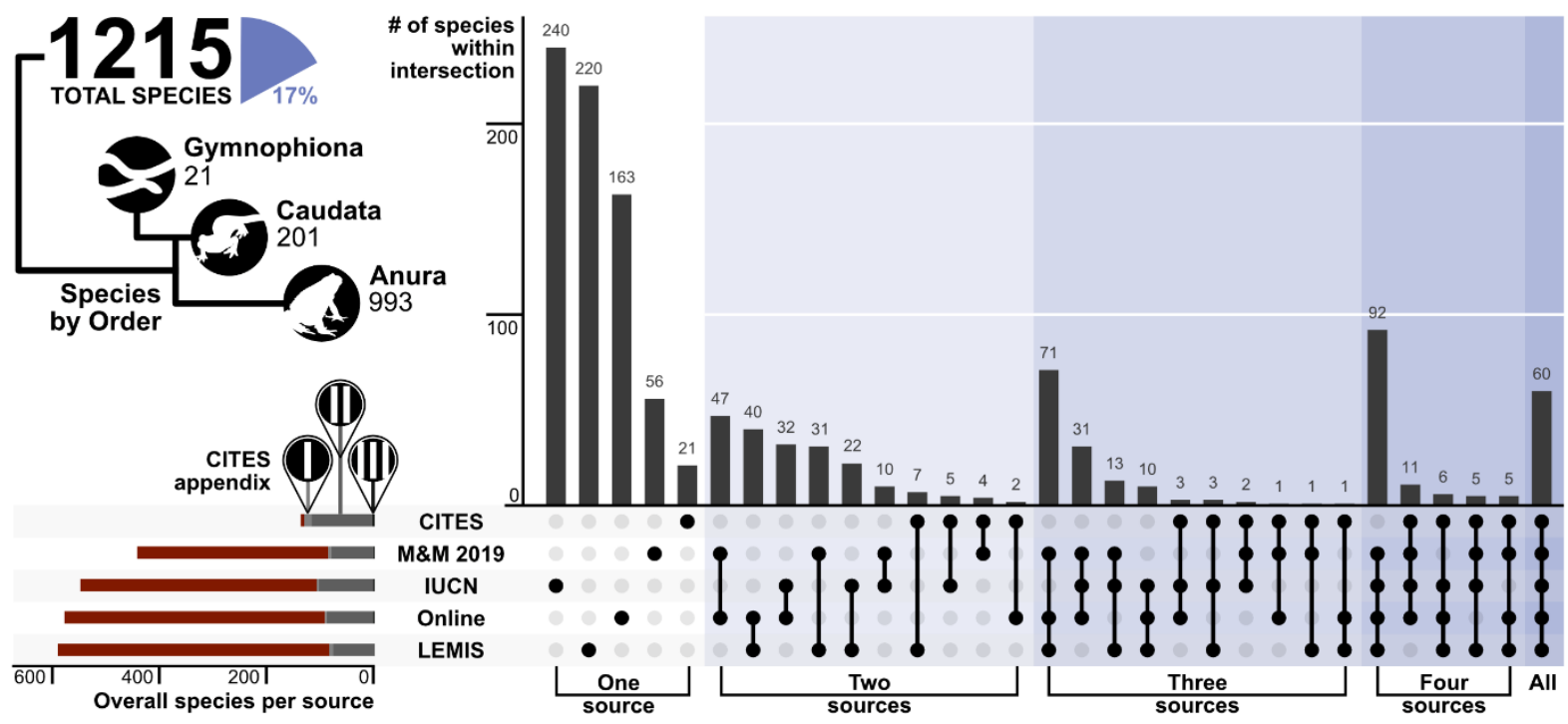

Figure. 7 


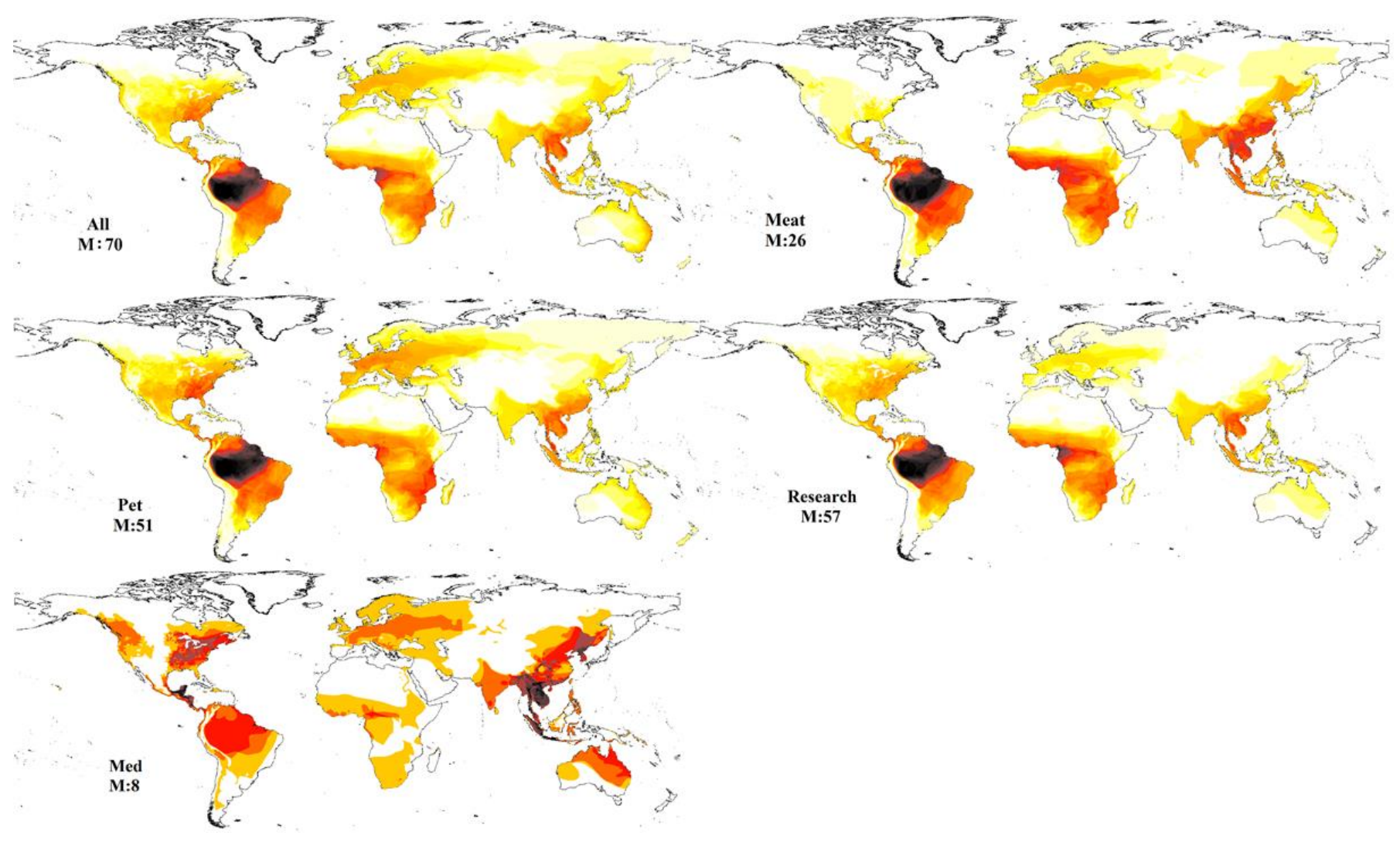

\section{Supplemental Figures}

Figure S1. Map of trade by country derived from the three main databases. 
bioRxiv preprint doi: https://doi.org/10.1101/2021.05.12.443752; this version posted May 13, 2021. The copyright holder for this preprint (which

was not certified by peer review) is the author/funder, who has granted bioRxiv a license to display the preprint in perpetuity. It is made available under aCC-BY 4.0 International license.

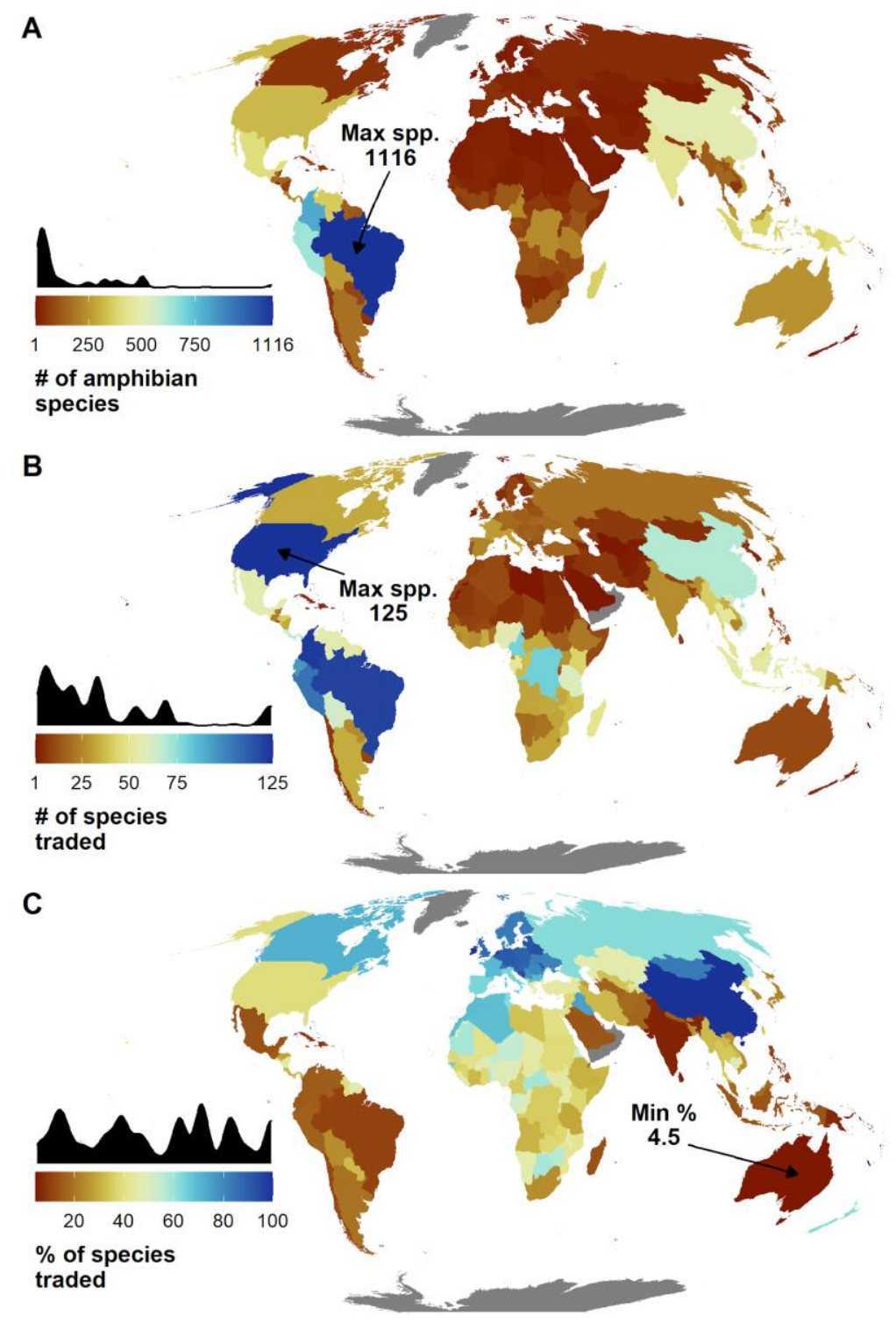

Figure S2. 
bioRxiv preprint doi: https://doi.org/10.1101/2021.05.12.443752; this version posted May 13, 2021. The copyright holder for this preprint (which

was not certified by peer review) is the author/funder, who has granted bioRxiv a license to display the preprint in perpetuity. It is made available under aCC-BY 4.0 International license.

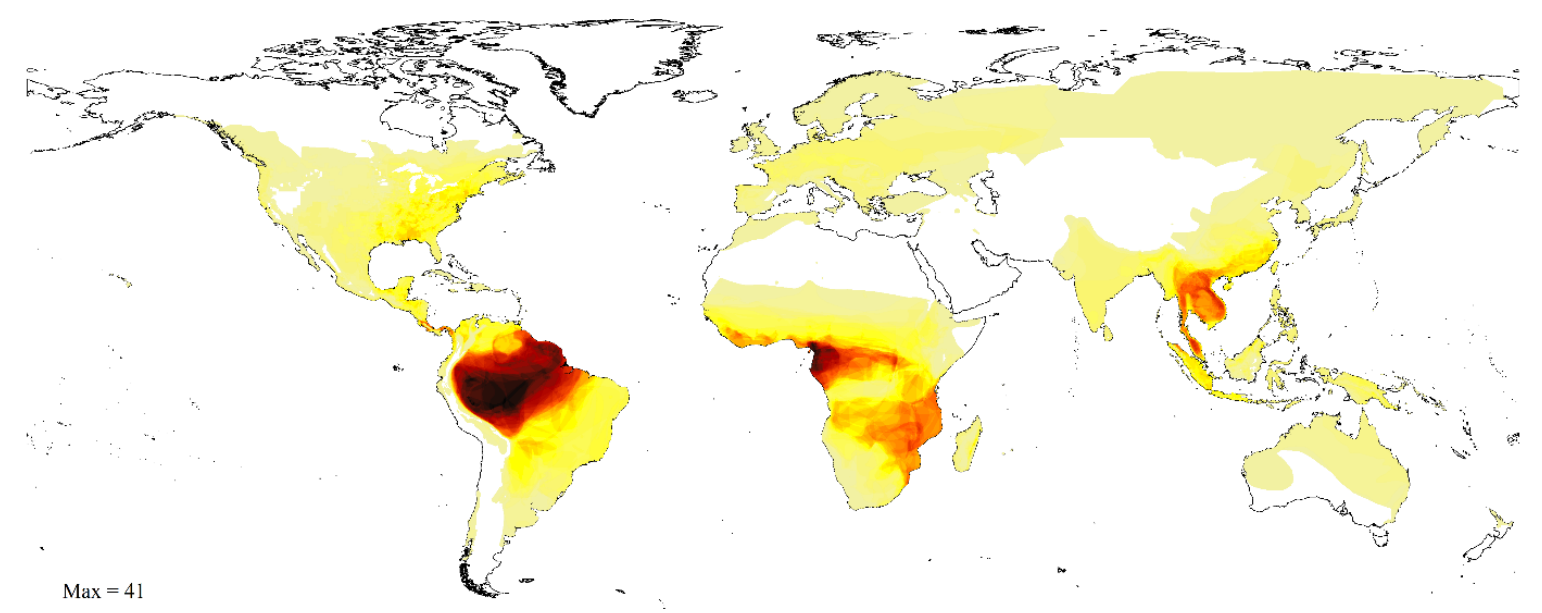

\section{a. LEMIS}

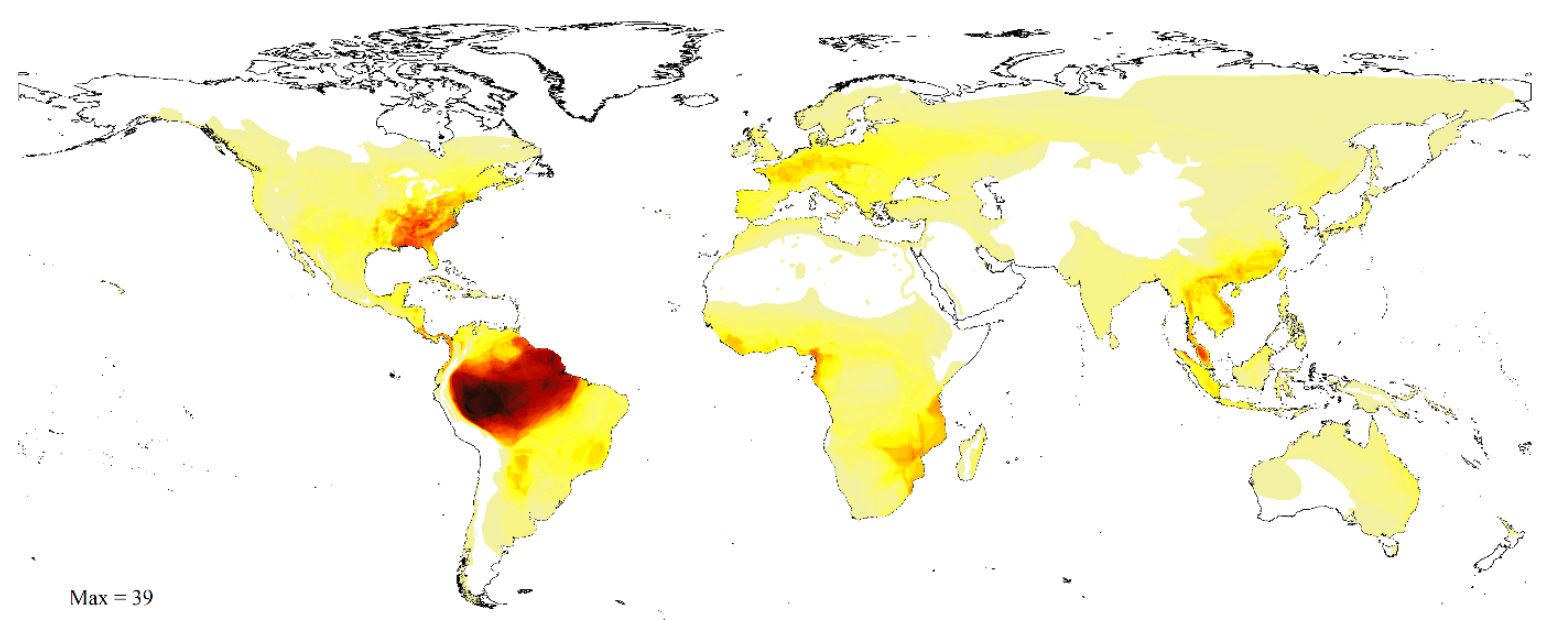

b. Online

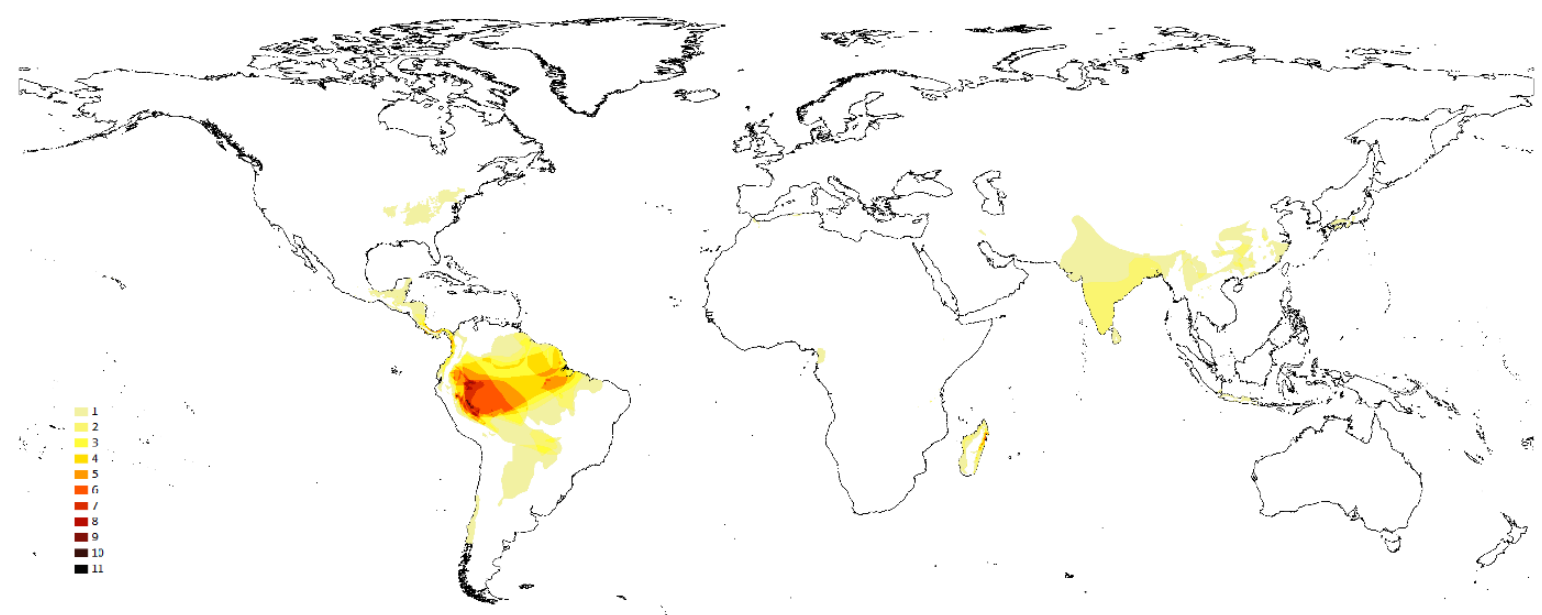

c. CITES 
Figure S3. Maps of National statistics of species with different IUCN Redlist status and CITES listing in trade.

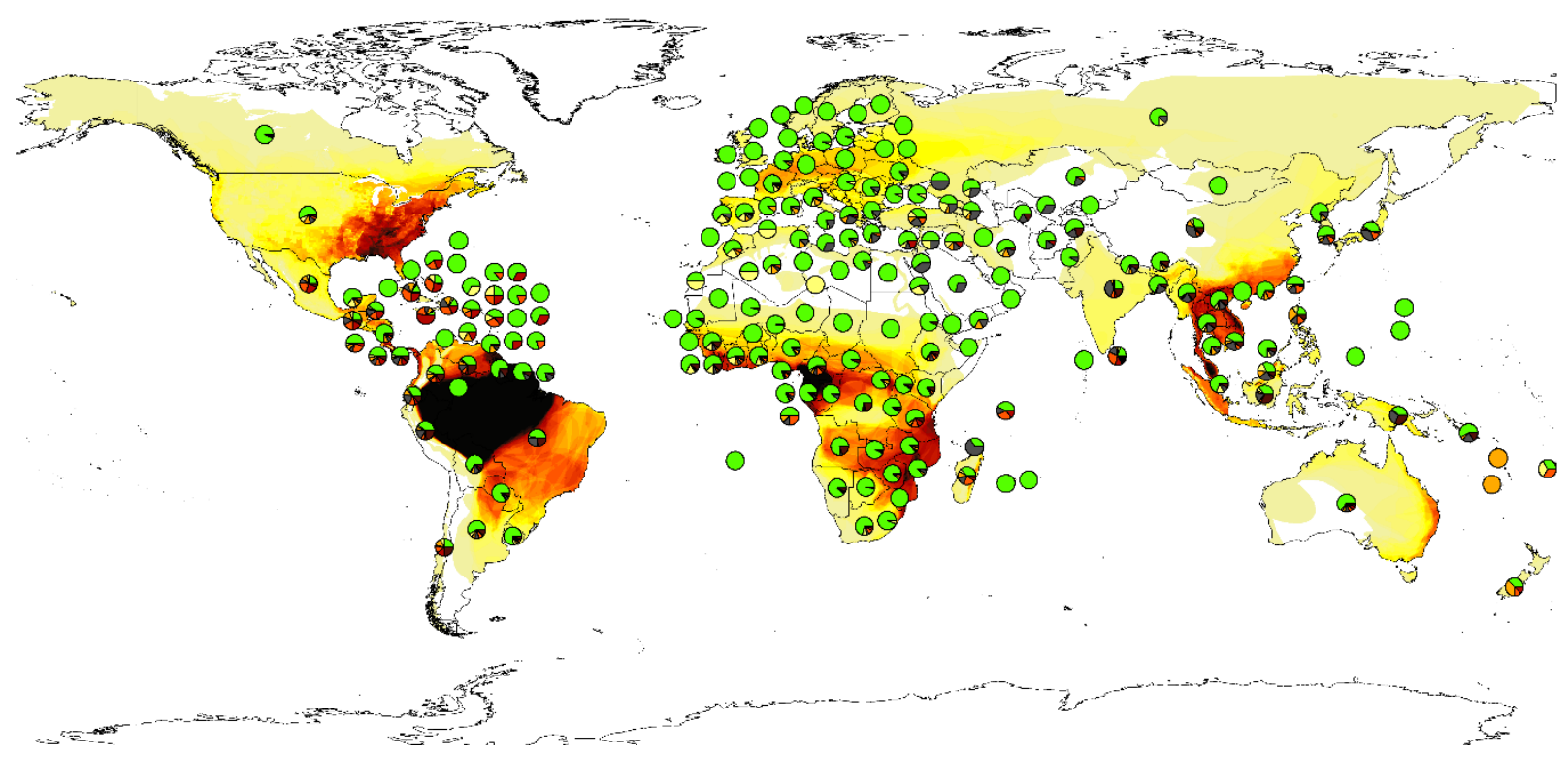

Species in trade by IUCN status: Green is Least Concern, Yellow is Near Threatened, Orange is Vulnerable, Red is Endangered, Dark red is Critically Endangered, Grey is Data Deficient or unassessed.

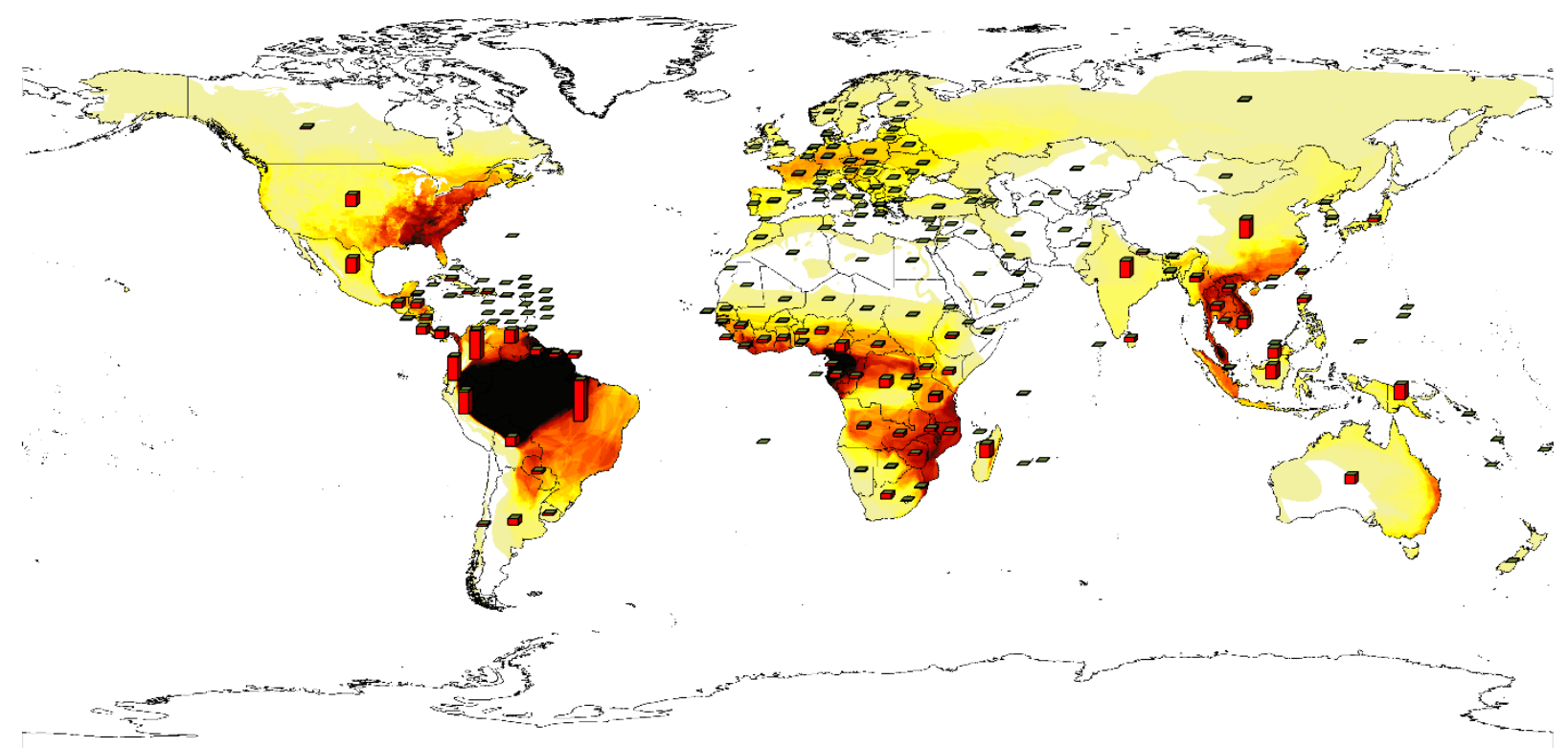

Species in trade by Appendix (Red: not CITES listed; Green: CITES listed) 
Figure S4. Threatened species in trade

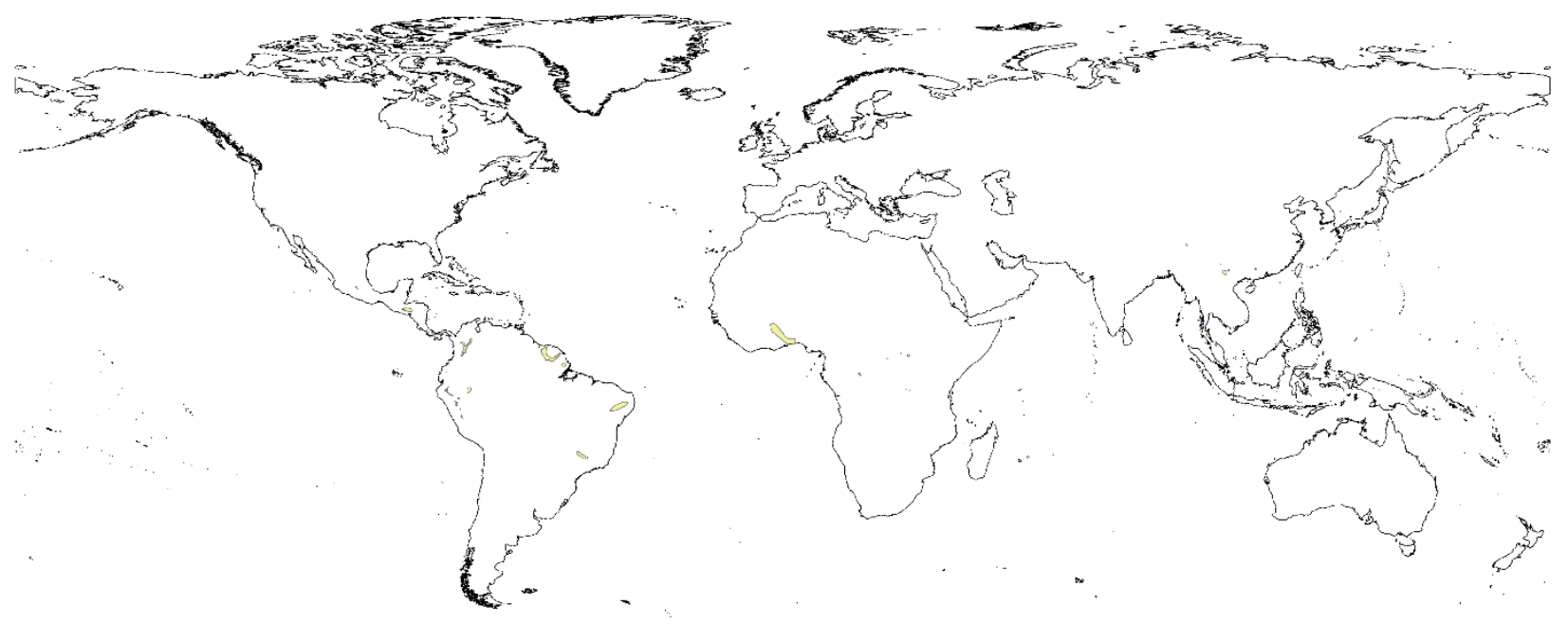

a. Data deficient species

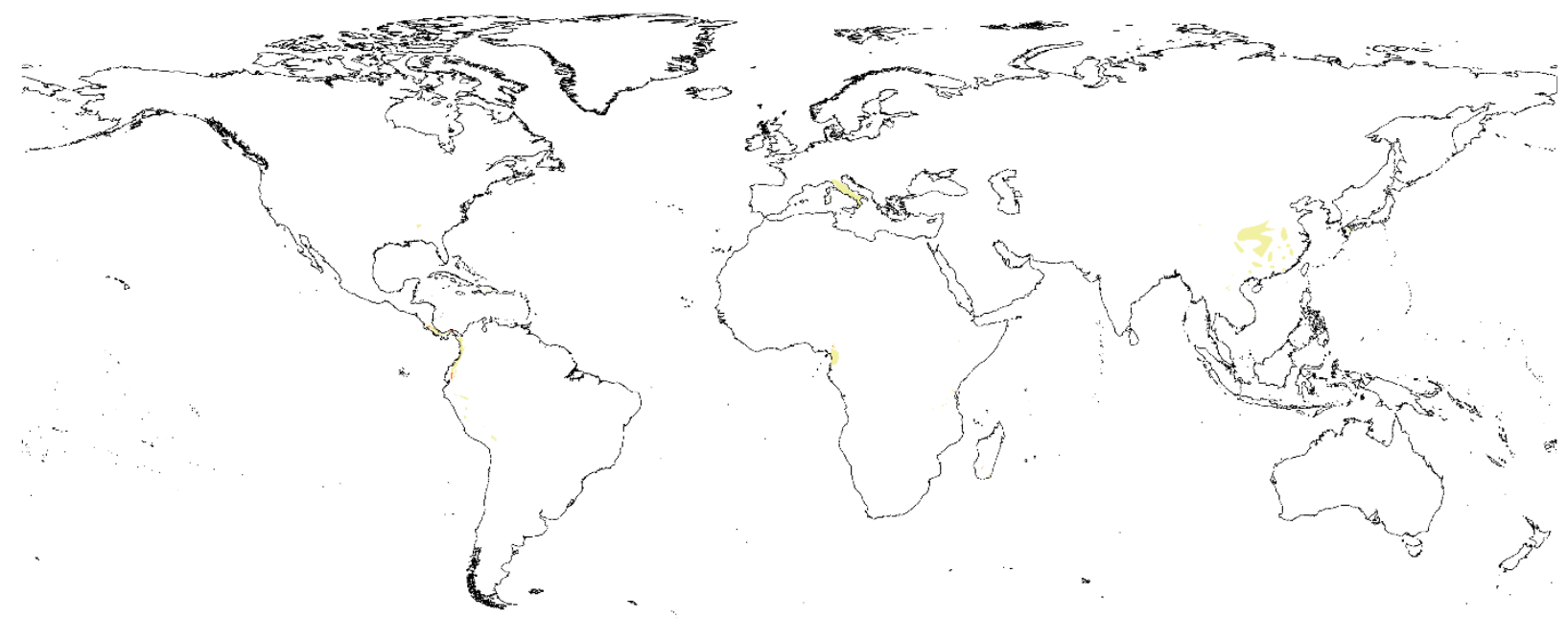

b. Endangered and critically endangered species 


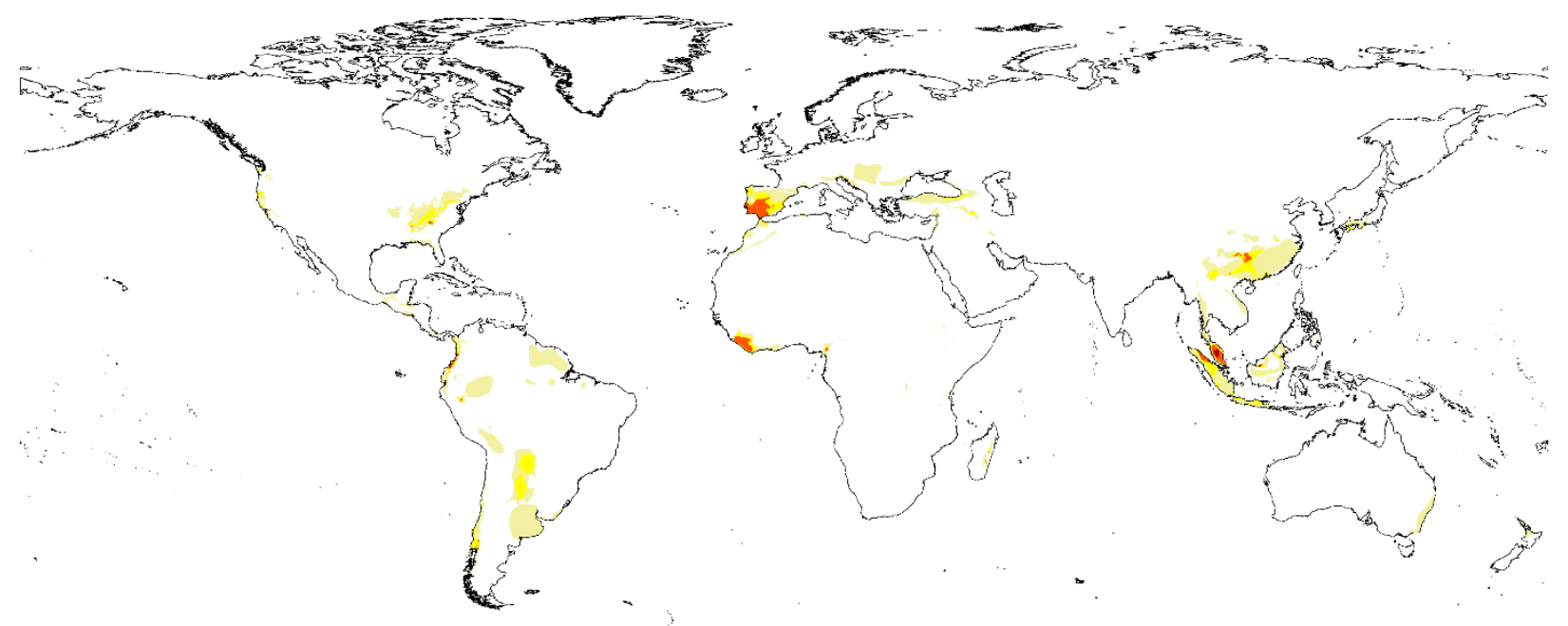

c. Vulnerable and near threatened species

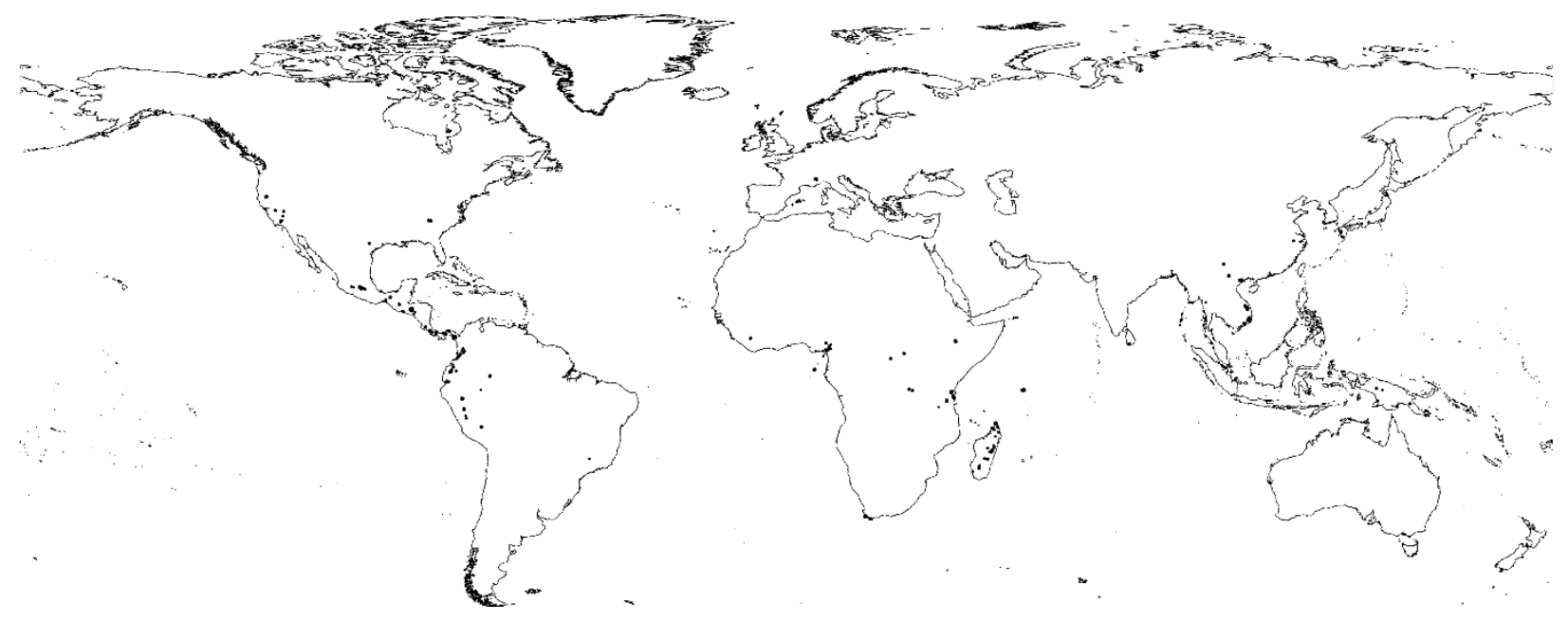

d. Small ranged species (under 1000km) 
Figure S5. Bar chart showing the number and origin of imported individuals per genera, subset to genera with over $1,000,000$ individuals recorded.

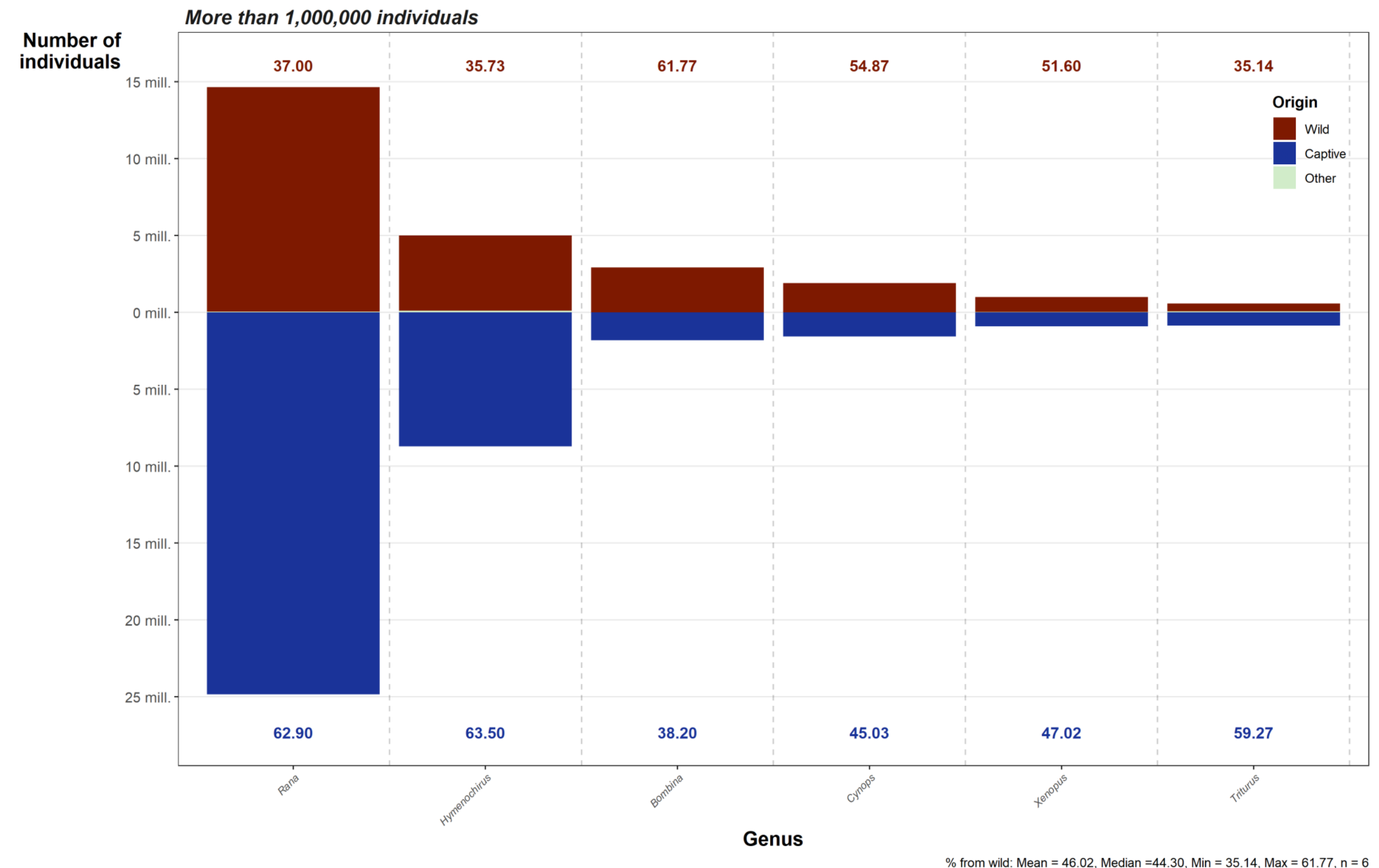


Figure S6. Bar chart showing the number and origin of imported individuals per genera, subset to genera with between $1,000,000$ and 100,000 individuals recorded.

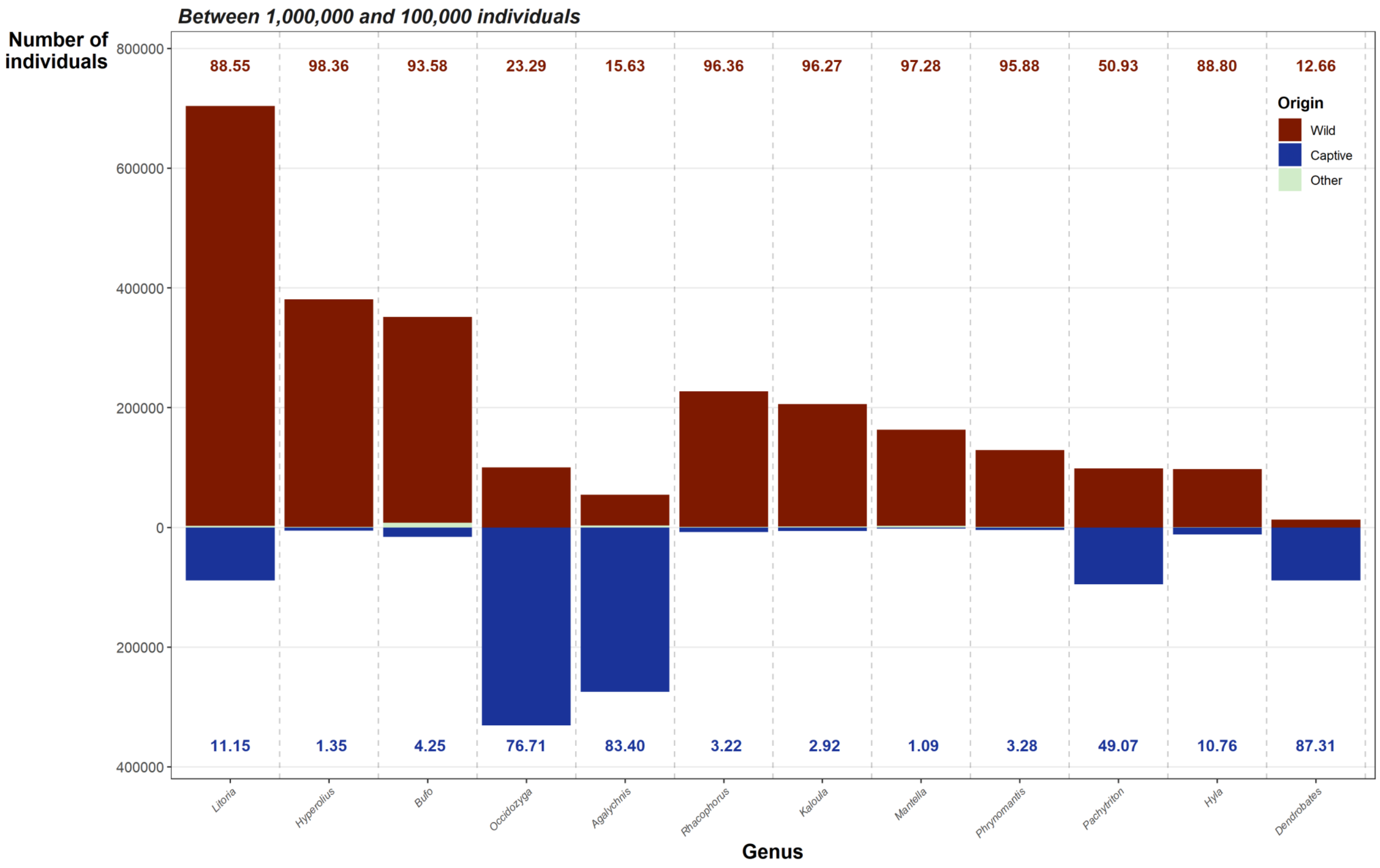


Figure S7. Bar chart showing the number and origin of imported individuals per genera, subset to genera with between 100,000 and 10,000 individuals recorded.

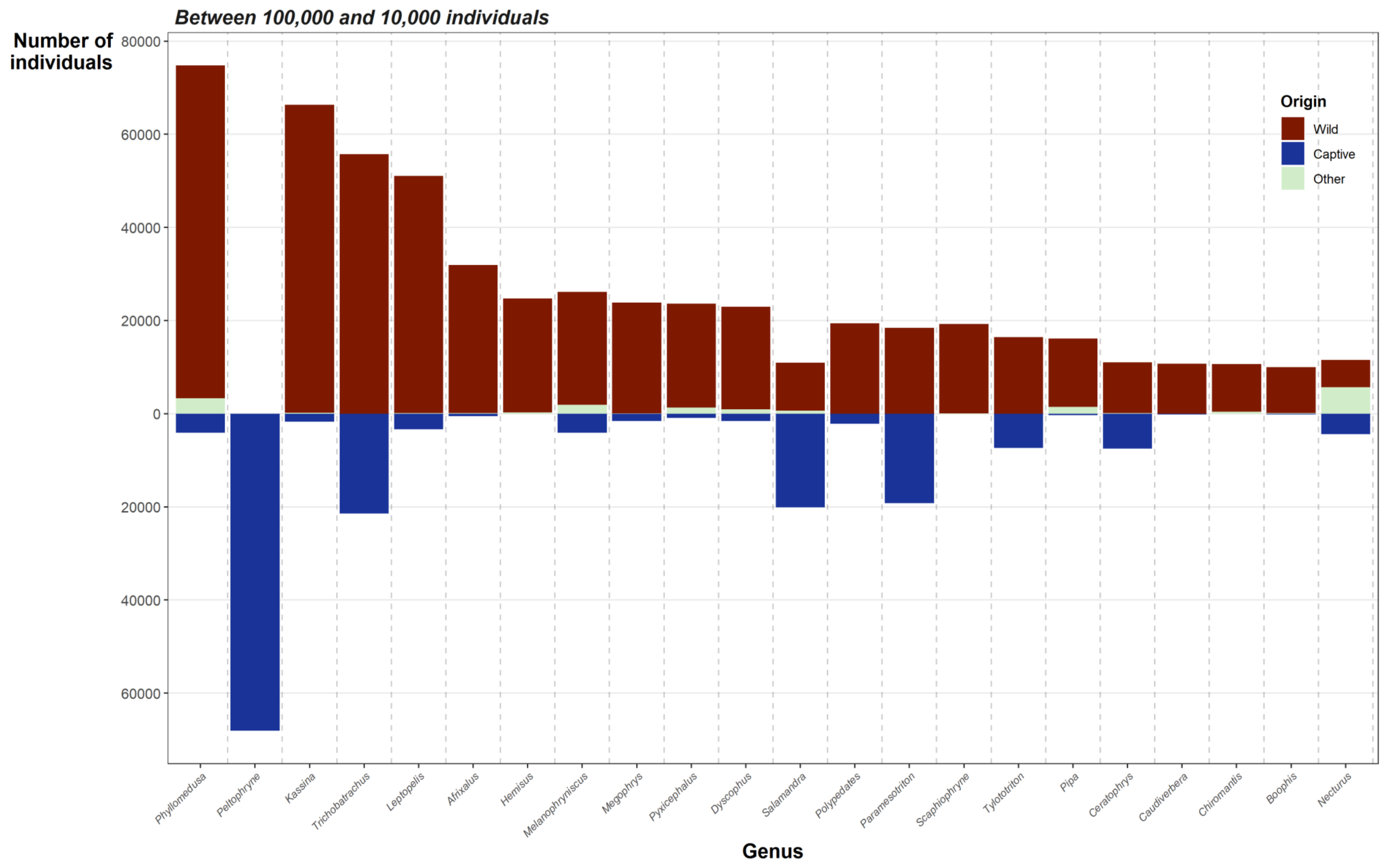


Figure S8. Bar chart showing the number and origin of imported individuals per genera, subset to genera with between 10,000 and 1,000 individuals recorded.

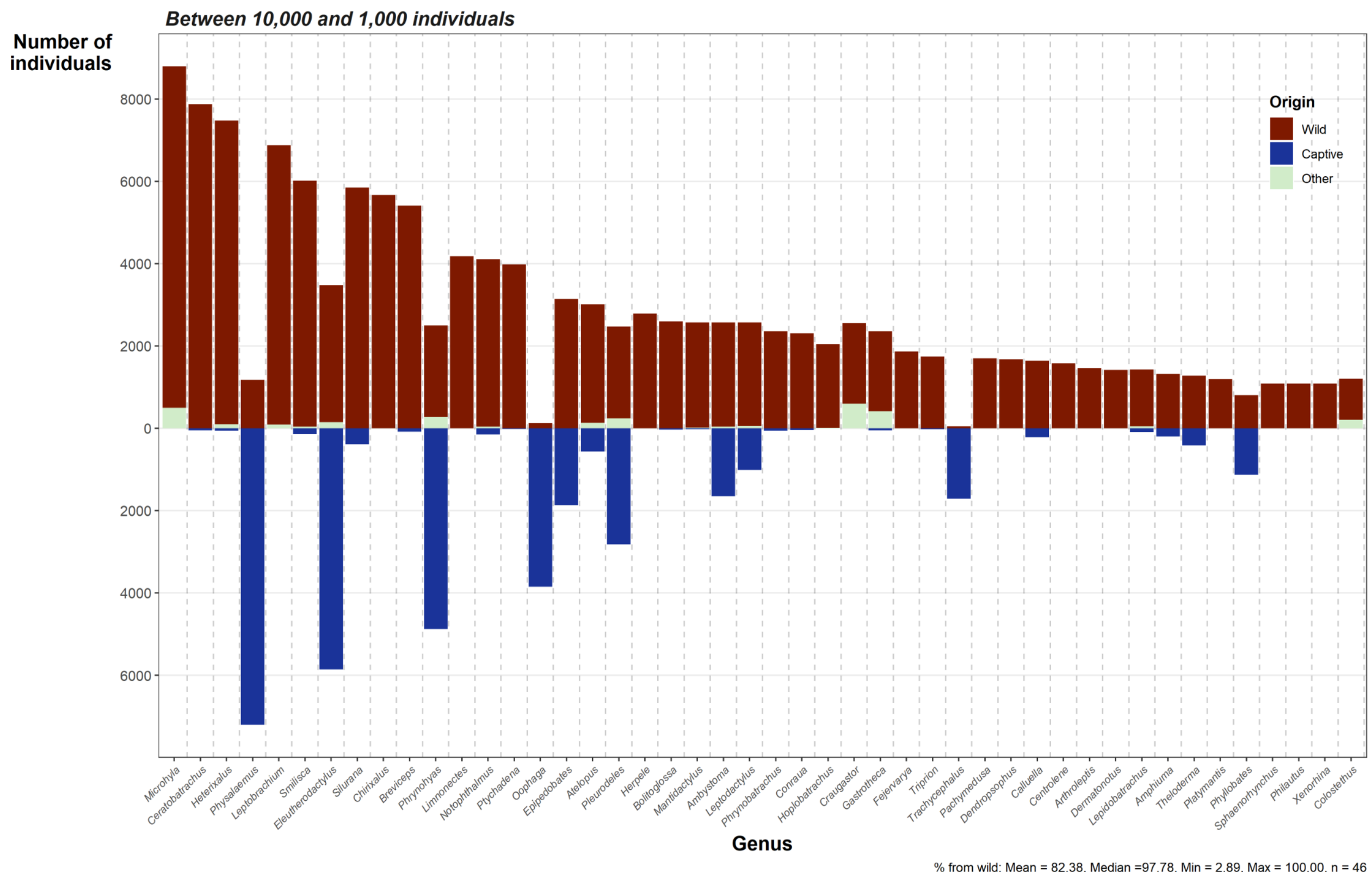


Figure S9. Bar chart showing the number and origin of imported individuals per genera, subset to genera with between 1,000 and 100 individuals recorded.

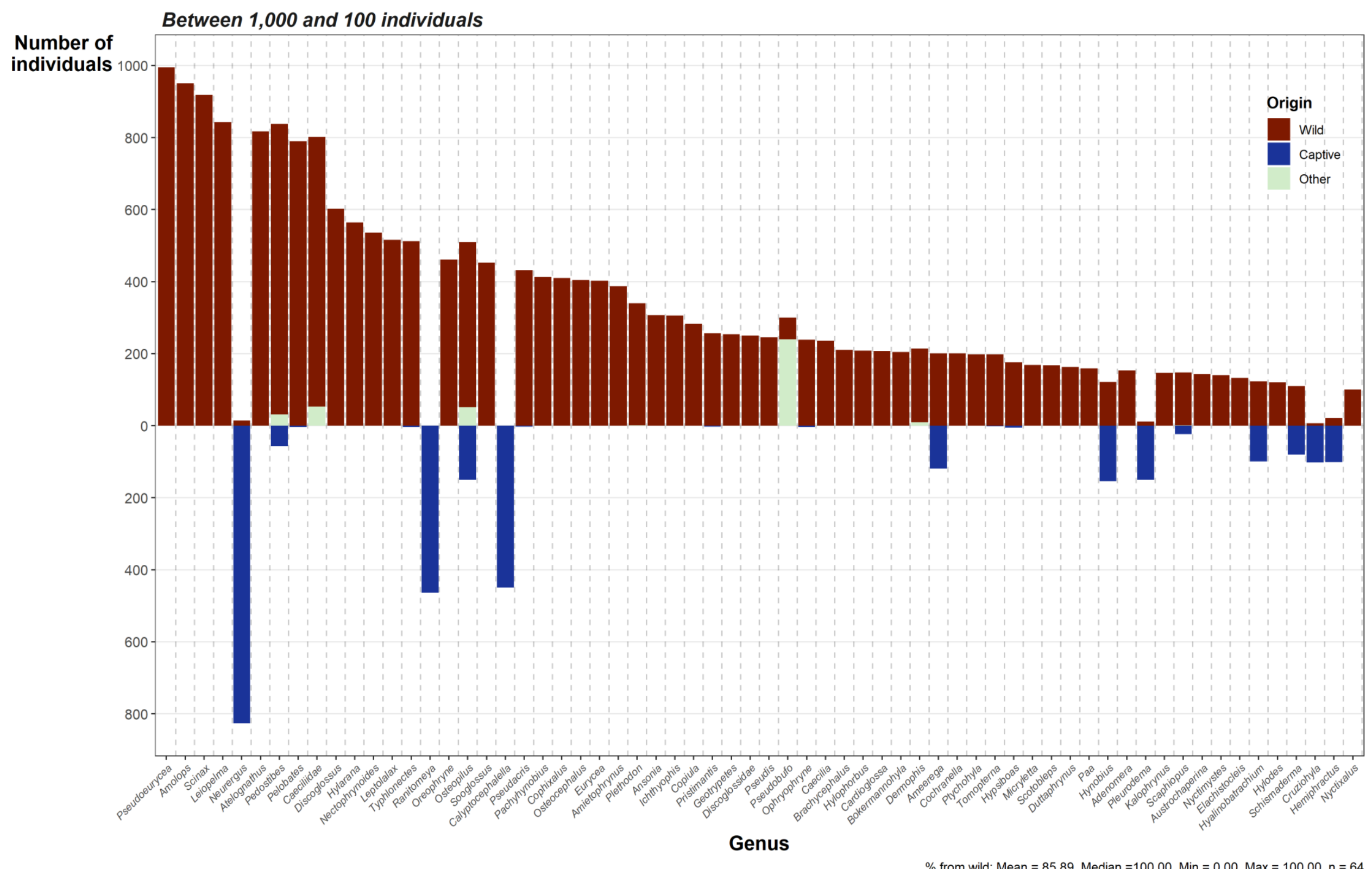


Figure S10. Bar chart showing the number and origin of imported individuals per genera, subset to genera with fewer than 100 individuals recorded.



